\title{
Acute kidney injury in
}

\section{trauma and cardiac arrest patients}

Thesis for the degree Philosophiae Doctor (Ph.D.)

cand.med. Sigrid Beitland

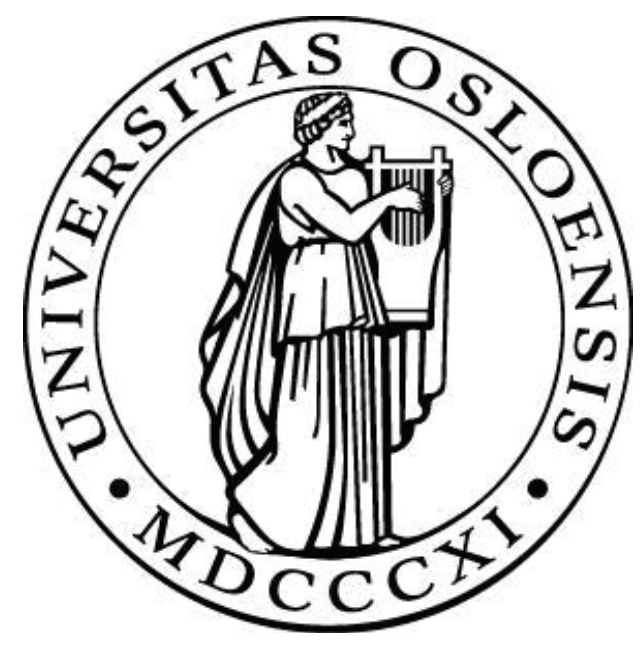

Institute of Clinical Medicine, Faculty of Medicine, University of Oslo

Department of Anaesthesiology, Division of Emergencies and Critical Care, Oslo University Hospital 
(C) Sigrid Beitland, 2017

Series of dissertations submitted to the

Faculty of Medicine, University of Oslo

ISBN 978-82-8333-360-2

All rights reserved. No part of this publication may be

reproduced or transmitted, in any form or by any means, without permission.

Cover: Hanne Baadsgaard Utigard.

Print production: Reprosentralen, University of Oslo. 


\section{Table of contents}

1. Acknowledgements....................................................... 7

2. Acronyms and abbreviations.............................................

3. List of papers............................................................. 11

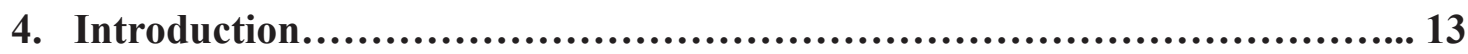

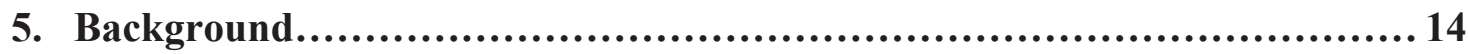

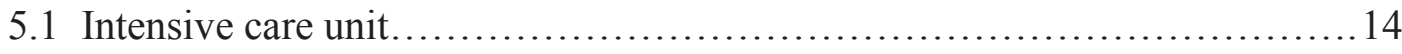

5.2 Trauma................................................................ 15

5.3 Cardiac arrest........................................................ 16

5.4 Acute kidney injury........................................... 18

5.4.1 Definitions................................................. 18

5.4 .2 Incidence................................................20

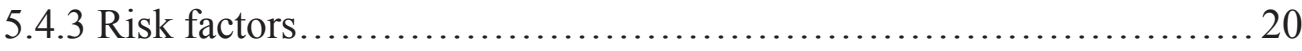

5.4.4 Pathophysiology.......................................... 22

5.4 .5 Prophylaxis................................................ 25

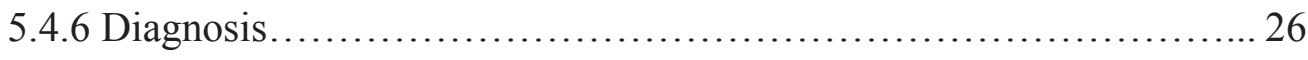

5.4.7 General supportive treatment................................ 29

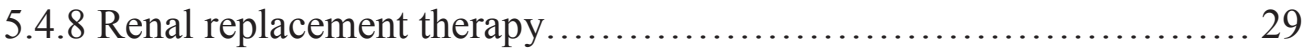

5.4 .9 Outcome................................................. 32

6. Aims and research questions.............................................. 33

7. Materials and methods...................................................... 34

7.1 Study setting and design......................................... 34

7.2 Study population................................................ 34

7.3 Ethical considerations and approvals................................... 36

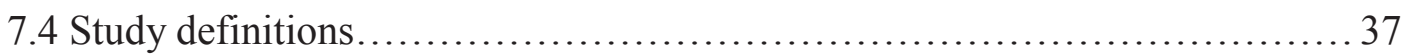


7.5 Data collection.................................................... 39

7.6 Laboratory assays.................................................. 40

7.7 Statistical analyses................................................ 41

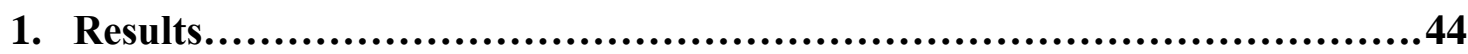

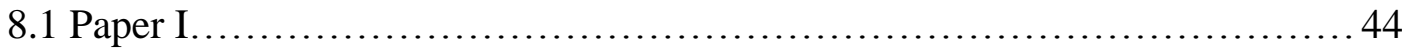

8.2 Paper II............................................................ 46

8.3 Paper III............................................................ 48

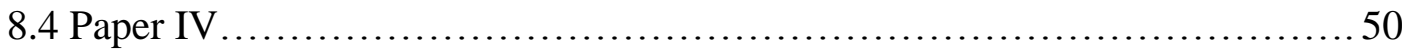

2. Discussion.......................................................................52

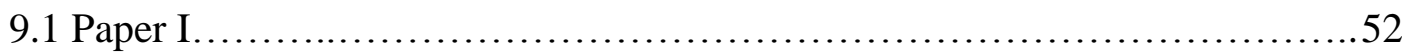

9.2 Paper II....................................................... 54

9.3 Paper III.............................................................. 56

9.4 Paper IV ....................................................... 59

9.5 Methodological considerations.....................................61

9.6 Implications for clinical practice and future research.....................65

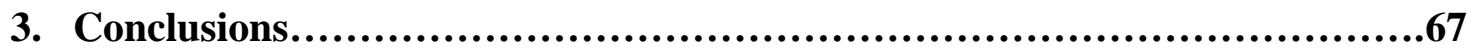

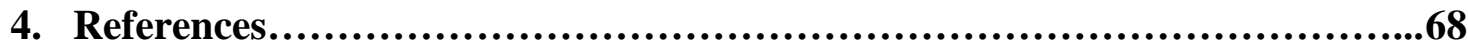

5. Reprints of Paper I-IV ......................................................84 


\section{Overview of tables and figures}

\section{Tables}

Table 1: Definitions and staging of acute kidney injury............................. 19

Table 2: Nephrotoxic drugs..................................................... 21

Table 3: Pathophysiological mechanisms involved in acute kidney injury................22

Table 4: Anatomical and physiological alterations in acute kidney injury...............23

Table 5: Biomarkers of acute kidney injury.................................... 28

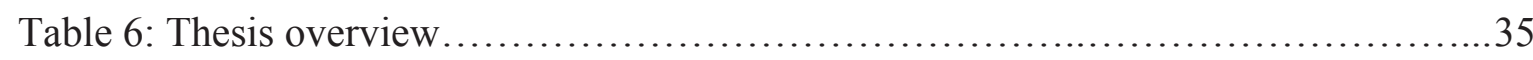

Table 7: Daily duration of continuous renal replacement therapy $\ldots \ldots \ldots \ldots \ldots \ldots \ldots \ldots . \ldots 4$

Table 8: Outcome in patients with and without renal replacement therapy............... 49

Table 9: Assessment of the quality of studies included in this thesis..................61

\section{Figures}

Figure 1: Time from trauma to initiation of renal replacement therapy $\ldots \ldots \ldots \ldots \ldots \ldots \ldots 45$

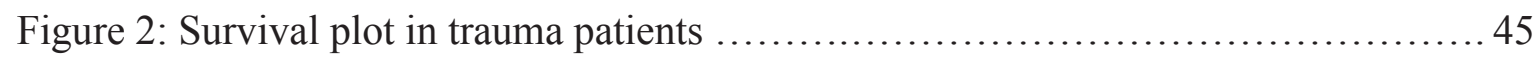

Figure 3: Blood sample analyses in trauma patients............................. 47

Figure 4: Time from cardiac arrest to initiation of renal replacement therapy ..............49

Figure 5: Receiver operating characteristics curves in cardiac arrest patients.............51 


\section{Acknowledgements}

I wish to express my sincere gratitude to all who supported, inspired and encouraged me during years of clinical practice and medical research, especially:

Kjetil Sunde (main supervisor) for being rapidly responding to all my questions, always hard working, and constantly aiming to improve patient care. Thank you for being my mentor in every aspect of my work, for our patience, and faith in me. Your support has been invaluable throughout my research, and this thesis would not exist without you.

Ingrid Os (co-supervisor) for your kind introduction to clinical research and major contribution to my PhD scholarship. I sincerely appreciate your inputs from a nephrologists' point of view, which has undoubtedly widened my understanding of kidney disease.

Torsten Eken (co-supervisor) for contributing with your genius skills in collection, analysis and presentation of data. I am forever grateful for your input in complex statistical analyses. Sven William Nissen and Erik Waage-Nielsen (anaesthesiologists) for introducing me to anaesthesiology, tolerantly teaching me the basic skills and appropriate manners.

Helge Opdahl, Harald Moen and Olav Stokland (intensive care physicians) who thought me the entire practical, theoretical and ethical aspects of intensive care medicine. Thank you for willingly sheering with me your enormous knowledge and experience and for all the outstanding practical and theoretical lectures you had. A special thanks to Harald who initiated this $\mathrm{PhD}$-project, and to Helge who introduced me to medical research. Nina Meidell, Kjell Olafsen, Per Kvandal, Annette Robertsen, Trine M. Gundem, Knut Gaustad, Elin Helset, Torleif Lorentsen and Are B. Tvinnerheim (intensive care physicians) for your everyday discussions and inputs, ensuring that we learn from each other, and improve together. I have always appreciated to discuss patients with you, keeping in mind the difference between statistical and clinical significance. Even though our workload is extremely heavy, you manage to sustain a nice atmosphere at our department. 
Colleges at the Department of Anaesthesiology for your cooperation and team work in handling the most severely ill patients. I am also grateful to the heads of the department giving me the opportunity to combine research and clinical work.

Morten Hestnes, Nils-Oddvar Skaga, Rolf Haagensen, Torbjørn Leivestad and Leiv Sandvik (research helpers) for your contributions to the papers in trauma patients.

Espen R. Nakstad, Henrik Stcer-Jensen, Tomas Dragni, Anne-Marie S. Trøseid, Berit S. Brusletto, Geir Ø. Andersen, Dag Jacobsen, Bård E. Waldum-Grevbo, Cathrine Brunborg and Jens-Petter Berg (research collaborators) who all contributed vastly to the papers in cardiac arrest patients. It has been a privilege and pleasure to work with you, I am proud of what we have accomplished together.

The ICU nursing staff, I would like to thank for your commitment to patients, you understanding of teamwork, and also for your collaboration in data collection.

Patients and their relatives, I would like to acknowledge your unconditional willingness to contribute to research at very critical moments of your lives.

My grandfather, who died way too early of kidney disease. Even though I never got the chance to meet you, you have been a constant reminder of the importance of my work. My mother and father, I would like to express gratitude for your unconditional love and support. I am grateful that you thought me to work hard and never give up.

My sisters and brother, who were my role models as a child. Thank you for always supporting and encouraging me, and for giving me insight into other aspects of life.

My bellowed Christian, I am forever grateful for you being so generous and wise, and for your enormous love and support. I am overwhelmed by your understanding and patience, giving me the opportunity to devote so much time to research.

My children Silje and Kjetil, always reassuring me that life is much more than research. You are providing me energy, challenging me, and giving me spirit every day. 


\section{Acronyms and abbreviations}

\begin{tabular}{|c|c|}
\hline $\mathrm{ACCP}$ & American college of chest physicians \\
\hline ACEI & Angiotensin converting enzyme inhibitor \\
\hline ADQI & Acute dialysis quality initiative \\
\hline AKI & Acute kidney injury \\
\hline AKIN & Acute kidney injury network \\
\hline ALS & Advanced life support \\
\hline $\mathrm{ARB}$ & Angiotensin II receptor blocker \\
\hline ARF & Acute renal failure \\
\hline ATN & Acute tubular necrosis \\
\hline ATPase & Adenosinetriphosphatase \\
\hline AuROC & Area under the receiver operating characteristics curve \\
\hline $\mathrm{BE}$ & Base excess \\
\hline BLS & Basic life support \\
\hline${ }^{\circ} \mathrm{C}$ & Degrees Celsius \\
\hline $\mathrm{CA}$ & Cardiac arrest \\
\hline $\mathrm{C}_{\mathrm{cr}}$ & Creatinine clearance \\
\hline CI & Confidence interval \\
\hline CI-AKI & Contrast-induced acute kidney injury \\
\hline $\mathrm{CK}$ & Creatine kinase \\
\hline CKD & Chronic kidney disease \\
\hline $\mathrm{cm}$ & Centimetres \\
\hline $\mathrm{CPC}$ & Cerebral performance category \\
\hline CPR & Cardiopulmonary resuscitation \\
\hline CRRT & Continuous renal replacement therapy \\
\hline CVVHD & Continuous veno-venous haemodialysis \\
\hline CVVHDF & Continuous veno-venous haemodiafiltration \\
\hline CVVHF & Continuous veno-venous haemofiltration \\
\hline DOI & Digital object identifier \\
\hline ECG & Echocardiogram \\
\hline eGFR & Estimated glomerular filtration rate \\
\hline ESRD & End-stage renal disease \\
\hline $\mathrm{F}$ & French \\
\hline GCS & Glasgow coma scale \\
\hline GFR & Glomerular filtration rate \\
\hline GN & Glomerulonephritis \\
\hline $\mathrm{h}$ & Hour \\
\hline $\mathrm{HCO}_{3}^{-}$ & Bicarbonate \\
\hline ICD & International classification of disease \\
\hline ICU & Intensive care unit \\
\hline IGFBP & Insulin-like growth factor-binding protein \\
\hline IHD & Intermittent haemodialysis \\
\hline IL & Interleukin \\
\hline ISS & Injury severity score \\
\hline IQR & Interquartile range \\
\hline K & Dialyzer clearance of urea \\
\hline $\mathrm{K}^{+}$ & Potassium \\
\hline KDIGO & Kidney disease - improving global outcome \\
\hline $\mathrm{kDa}$ & Kilo Dalton \\
\hline
\end{tabular}




\begin{tabular}{|c|c|}
\hline $\mathrm{kg}$ & Kilogram \\
\hline KIM & Kidney injury molecule \\
\hline $\mathrm{L}$ & Litre \\
\hline L-FABP & Liver-type fatty acid-binding protein \\
\hline $\mathrm{m}$ & Mili \\
\hline $\mathrm{m}^{2}$ & Square meter \\
\hline MDRD & Modification of diet in renal disease \\
\hline $\min$ & Minute \\
\hline$\mu$ & Micro \\
\hline $\mathrm{n}$ & Number \\
\hline $\mathrm{Na}^{+}$ & Sodium \\
\hline NCT & National clinical trial \\
\hline NGAL & Neutrophil gelatinase-associated lipocalin \\
\hline NORCAST & Norwegian cardiorespiratory arrests study \\
\hline NSAID & Non-steroid anti-inflammatory drug \\
\hline OHCA & Out-of-hospital cardiac arrest \\
\hline OR & Odds ratio \\
\hline OUHU & Oslo university hospital Ullevål \\
\hline $\mathrm{P}_{\mathrm{Cr}}$ & Plasma creatinine concentration \\
\hline PD & Peritoneal dialysis \\
\hline PEA & Pulseless electric activity \\
\hline $\mathrm{pH}$ & Pondus hydrogenii \\
\hline $\mathrm{PhD}$ & Philosophiae Doctor \\
\hline PNO & Poor neurological outcome \\
\hline $\mathrm{r}$ & Correlation coefficient \\
\hline $\mathrm{RCF}$ & Relative centrifugal force \\
\hline RIFLE & Risk, injury, failure, loss and end-stage renal disease \\
\hline ROC & Receiver operating characteristics \\
\hline ROS & Reactive oxygen species \\
\hline ROSC & Return of spontaneous circulation \\
\hline RRT & Renal replacement therapy \\
\hline RTS & Revised trauma score \\
\hline SAPS & Simplified acute physiology score \\
\hline SCCM & Society of critical care medicine \\
\hline $\mathrm{S}_{\mathrm{Cr}}$ & Serum creatinine concentration \\
\hline $\mathrm{SD}$ & Standard deviation \\
\hline SIRS & Systemic inflammatory response syndrome \\
\hline SOFA & Sequential organ failure assessment \\
\hline SOP & Standard operating procedure \\
\hline SPSS & Statistical package for social sciences \\
\hline $\mathrm{t}$ & Time \\
\hline TIMP & Tissue inhibitor of metalloproteinase \\
\hline TLR & Toll-like receptor \\
\hline TNF & Tumour necrosis factor \\
\hline TTM & Targeted temperature management \\
\hline $\mathrm{U}_{\mathrm{Cr}}$ & Creatinine concentration in urine \\
\hline $\mathrm{V}$ & Volume of distribution for urea \\
\hline Vdt & Urine flow rate \\
\hline VF & Ventricular fibrillation \\
\hline VT & Ventricular tachycardia \\
\hline
\end{tabular}




\section{List of papers}

\section{Paper I}

Beitland S, Moen H, Os I. Acute kidney injury with renal replacement therapy in trauma patients. Acta Anaesthesiol Scand 2010; 54(7): 833-40.

DOI (digital object identifier): 10.1111/j.1399-6576.2010.02253.x

\section{Paper II}

Beitland S, Sunde K, Moen H, Os I. Variability in Uremic Control during Continuous Venovenous Hemodiafiltration in Trauma Patients. Crit Care Res Pract 2012; 869237. DOI: $10.1155 / 2012 / 869237$

\section{Paper III}

Beitland S, Nakstad ER, Stær-Jensen H, Drægni T, Andersen GØ, Jacobsen D, Brunborg C, Waldum-Grevbo BE, Sunde K. Impact of acute kidney injury on patient outcome in out-ofhospital cardiac arrest: A prospective observational study. Acta Anaesthesiol Scand 2016; 60(8):1170-81.

DOI: $10.1111 /$ aas.12753

\section{Paper IV}

Beitland S, Waldum-Grevbo BE Nakstad ER, Berg JP, Trøseid AMS, Brusletto BS, Brunborg C, Andersen GØ, Sunde K. Urine biomarkers early predict acute kidney injury and patient outcome after out-of-hospital cardiac arrest. Crit Care 2016; 20(1):314.

DOI: 10.1186/s13054-016-1503-2 


\section{Introduction}

Acute kidney injury (AKI) is a feared complication in intensive care unit (ICU) patients where the kidneys rapidly fail to regulate fluid and/or metabolic waste products in the body [1-4]. AKI is quite common in ICU patients $[5,6]$, with variable incidence rates depending on the population studied and definitions used. The structural damage and/or functional impairment of the kidneys are caused by chronic risk factors acting together with acute illnesses and/or injuries [7-10]. Treatment of AKI is correction of the underlying condition and general supportive care of organ functions; the most severe cases need renal replacement therapy (RRT) temporary replacing the normal blood-filtering function of the kidneys [11]. AKI is associated with increased short-time morbidity, mortality and health care costs [12-15]. Survivors are also predisposed to chronic kidney disease (CKD) and have reduced long-time survival [16-19].

A better understanding of the pathophysiology of AKI has emerged in recent years [20-22] and uniform definitions are developed [23-25]. There are, however, still many shortcomings in the understanding of the disease process and patient care $[26,27]$. One is that AKI is a quite heterogeneous condition [5] with deficient understanding of different patients groups and treatment alternatives [11,28-32]. Another is that mortality in ICU patients with AKI remains high despite many attempts to improve prevention and treatment [32-35]. Finally, AKI becomes clinically evident when the decline in kidney function is quite advanced [36, 37], and it would be preferable to have early predictive biomarkers $[38,39]$.

This thesis focuses upon AKI in trauma- and out-of-hospital cardiac arrest (OHCA) patients who are two relatively small and heterogeneous subgroups of ICU patients. The primary aims were to investigate the occurrence of AKI and impact on patient outcome in both patient groups. Secondary aims were to evaluate the quality of RRT in trauma patients, and to examine the utility of urine AKI biomarkers in OHCA patients. 


\section{Background}

\subsection{Intensive care unit}

An ICU is a hospital department that provides highly specialized health care to patients with severe and life-threatening illnesses and/or injuries. ICU departments may consist of variable patient groups such as mixed-, surgical-, medical-, neurological- or paediatric ICUs.

Critically ill patients have reversible latent or manifest failure of one or several organ functions, including the central nervous system, cardiovascular system, lungs, liver, kidneys and coagulation system. ICU patients require constant, close monitoring and support from specialized equipment and medications to ensure improvement of these organ functions. The personnel working in the ICU are multidisciplinary consisting of doctors, nurses, physiotherapists and other groups working in teams closely following each patient. Among critically ill patients there is a substantial acute morbidity and mortality, and among survivors many suffer long-time physical and/or psychic disability [40, 41].

A huge challenge in the interpretation of studies performed in the ICU is that there is a considerable variation in critical care services across the world $[42,43]$. There is large siteto-site variability in the ICU population, the treatment they receive, and their outcomes limiting the external validity of ICU studies [42]. In order to overcome these shortcomings, validated scoring systems are developed in order to have uniform reporting systems enabling comparisons of patient cohorts. The severity of illness early during ICU stay may be assessed by the Simplified acute physiology score (SAPS) [44], and the extent of organ failures during ICU stay might be measured using the Sequential organ failure assessment (SOFA) score $[45]$. 


\subsection{Trauma}

Trauma mainly affects young males and is the sixth leading cause of death and the fifth leading cause of significant disability worldwide [46, 47]. Trauma mechanisms are typically motor vehicle accidents or falls, and is often divided into non-penetrating (blunt) and penetrating injuries. The severity of trauma is usually assessed using the Injury severity score (ISS) [48], major trauma is often defined as ISS above 15 [47]. Pre-hospital stabilization includes management of airway, breathing and circulation in addition to securing the patient with a cervical collar and a scoop stretcher [49]. Rapid transportation of severely injured patients directly to a trauma centre improves outcome [49].

In-hospital management by a multidisciplinary trauma team includes a primary survey to detect organ dysfunctions and injuries. After immediate care of life-threatening injuries that might include surgery, a secondary survey is performed with a more detailed head-to-toe assessment [49]. Post-trauma care has changed during the last years, especially regarding the handling of severe bleeding. Recent European guidelines recommend the use of early imaging techniques for detection of free fluid in patients with suspected torso trauma, and that patients with significant intra-thoracic, intra-abdominal or retroperitoneal bleeding and haemodynamic instability undergo urgent intervention [50]. In parallel to this, acute bleeding patients are treated with hypotensive resuscitation with restricted use of fluids, massive transfusion protocols including blood component therapy, as well as treatment of acidosis and hypothermia [50]. Immediate post-traumatic deaths are usually due to apnoea, severe brain injury or severe, uncontrolled bleeding leading to circulatory collapse. In contrast, late deaths are often related to infections, organ complications or withdrawing of treatment due to futility. Among survivors, massive tissue injury, bleeding, coagulopathy and/or infection after trauma may severely affect organ functions; the kidney function is further challenged by skeletal muscular necrosis, i.e. rhabdomyolysis. 
The incidence of AKI in trauma patients is estimated to be $15-48 \%$ [51-56], but more robust data are warranted. Post-traumatic AKI is only a small proportion of severe AKI observed in the ICU [5]. There are few trauma patients in need of RRT, and usually the kidney function is restored in survivors [10]. Important risk factors for post-traumatic AKI are pre-existing CKD and other co-morbidities, advanced age, African-American race, obesity, severe injuries, rhabdomyolysis, blood product administration, haemoperitoneum and mechanical ventilation [10,57-59]. Importantly, development of AKI in trauma patients is associated with increased patient mortality $[51,54,55,60,61]$. Trauma survivors may end up with long time complications including pain, reduced quality of life, physical disability and/or post-traumatic stress disorder $[62,63]$.

\subsection{Cardiac arrest}

Cardiac arrest (CA) is one of the most common causes of death in industrialised countries mainly affecting male, middle-aged and/or elderly people [64, 65]. In a recent European multinational study the incidence rate of OHCA was on average 84 per 100.000 inhabitants per year with large variation across countries [66]. Cardiac causes, as acute myocardial infarctions, chronic ischemia and acute primary arrhythmias are the most frequent causes of arrest. Non-cardiac causes, like respiratory disease, cerebrovascular disease, trauma, asphyxia and intoxications have a worse prognosis $[67,68]$. OHCA is most often grouped according to the initial cardiac rhythm registered on the echocardiogram (ECG), i.e. ventricular tachycardia (VT), ventricular fibrillation (VF), pulseless electric activity (PEA) or asystole. The shockable rhythms (VT and VF) are usually associated with cardiac aetiology, PEA represents a wide range of aetiologies, and asystole is often the terminal rhythm as a sign of severe asphyxia $[69,70]$. CA patients must receive immediate cardiopulmonary resuscitation (CPR) in order to achieve return of spontaneous circulation (ROSC). CPR has traditionally been divided into 
basic life support (BLS) provided by bystanders consisting of chest compression and rescue breathing, and advanced life support (ALS) delivered by health-care professionals adding defibrillation, advanced airway management and intravenous drug therapy. Data from a large study indicate that $28 \%$ of OHCA victims achieve pre-hospital ROSC, and as many as $59 \%$ are transported to hospital, but again with large variations across sites [71]. The quality of care depends on five factors in the so-called "chain of survival": Immediate recognition of the CA, early CPR, early defibrillation, early ALS and post-resuscitation care [72].

In-hospital treatment after CA has improved during the last years focusing upon development of standard operating procedures (SOP) involving coronary reperfusion, targeted temperature management (TTM), haemodynamic optimisation in addition to control of seizures and blood sugar levels [73-75]. Initial survivors after CA have considerable morbidity and mortality $[76,77]$ related to the so-called post cardiac arrest syndrome $[78,79]$ characterized by ischemia and/or reperfusion injuries, activation of coagulation and inflammation, and subsequent occurrence of multiple organ failure [78, 79].

AKI affects $12-81 \%$ of the CA survivors and becomes clinical evident median 1-2 days after the arrest [80-85]. Between 4-33\% of patients with AKI will need RRT [81, 84-86], but only a small proportion of those are RRT dependent after 30 days [85]. Risk factors for AKI in CA victims are pre-existing renal insufficiency, non-shockable rhythm, long time to ROSC and post-resuscitation shock [85]. Development of AKI in CA victims is associated with increased risk of death [81, 84-86], whereas the impact on neurological outcome remains unsettled $[82,84,86]$. Neurological outcome after CA is usually assessed using the Cerebral Performance category (CPC) ranging from 1 to 5, stages 1 or 2 are considered to be a good functional outcome $[87,88]$. 


\subsection{Acute kidney injury}

AKI, previously named acute renal failure (ARF), must clearly be separated from CKD where there is progressive loss in kidney function evolving over a period above three months.

\subsubsection{Definitions}

Historically, there has been a huge challenge regarding the characterization of AKI as there were many different definitions that has hindered clinical research since it confounded comparisons between studies. In order to improve this, the Acute Dialysis Quality Initiative (ADQI) group developed the RIFLE (Risk, injury, failure, loss and end-stage renal disease) definition in 2004 [23]. The Acute Kidney Injury Network (AKIN) group published a slightly modified version in the AKIN definition in 2007 [24]. Later, the Kidney disease - improving global outcome (KDIGO) group published the KDIGO criteria in 2012 [25]. In all three definitions, the development of AKI has to be acute, and the worst of the serum creatinine and urine output criteria is used (Table 1). All definitions consider three variables related to:

- Time criteria: The change in kidney function has to be acute

- Glomerular criteria : Blood sample results and/or need of RRT

- Diuresis criteria: Urine output (measured as millilitre $(\mathrm{mL}) /$ kilogram $(\mathrm{kg}) / \mathrm{hour}(\mathrm{h}))$

More recently, some have suggested that novel biomarkers of AKI should be included in AKI definitions, because biomarkers can identify kidney damage not otherwise detected [89]. A similar approach has been used in CKD where patients with normal or elevated estimated glomerular filtration rate (eGFR) have been included in they have other signs of kidney damage in blood samples, urine samples or imaging studies [90]. Although this might be a promising new era of AKI staging, biomarkers have yet not been included in AKI definitions. 
Table 1: Definitions and staging of acute kidney injury

\section{Time period}

\section{RIFLE}

Serum creatinine changes over 1-7 days, sustained for more than 24 hours

\section{AKIN}

Acute serum creatinine changes occur within a 48 -hour period during hospitalization

\section{KDIGO}

Serum creatinine changes $\geq 1.5$ times baseline within 7 days*, or increases $\geq 26.5 \mu \mathrm{mol} / \mathrm{L}$ within a 48-hour time period**

\section{Serum creatinine criteria}

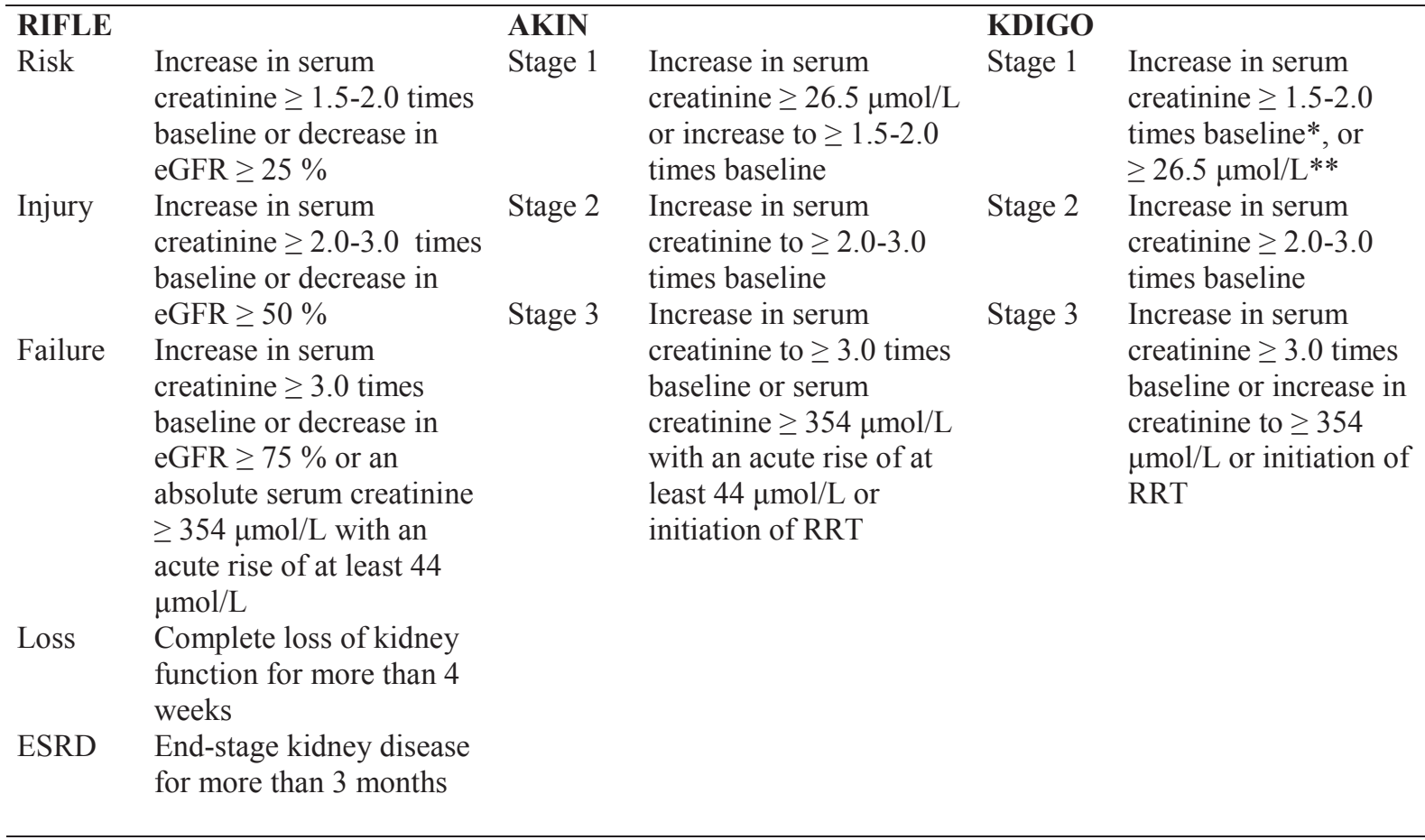

\section{Urine output criteria}

\begin{tabular}{|c|c|c|c|c|c|}
\hline \multicolumn{2}{|l|}{ RIFLE } & \multicolumn{2}{|l|}{ AKIN } & \multicolumn{2}{|l|}{ KDIGO } \\
\hline Risk & $\begin{array}{l}<0.5 \mathrm{~mL} / \mathrm{kg} / \mathrm{h} \text { for }>6 \\
\text { hours }\end{array}$ & Stage 1 & $\begin{array}{l}<0.5 \mathrm{~mL} / \mathrm{kg} / \mathrm{h} \text { for }>6 \\
\text { hours }\end{array}$ & Stage 1 & $\begin{array}{l}<0.5 \mathrm{~mL} / \mathrm{kg} / \mathrm{h} \text { for }>6 \\
-12 \text { hours }\end{array}$ \\
\hline Injury & $\begin{array}{l}<0.5 \mathrm{~mL} / \mathrm{kg} / \mathrm{h} \text { for }>12 \\
\text { hours }\end{array}$ & Stage 2 & $\begin{array}{l}<0.5 \mathrm{~mL} / \mathrm{kg} / \mathrm{h} \text { for }>12 \\
\text { hours }\end{array}$ & Stage 2 & $\begin{array}{l}<0.5 \mathrm{~mL} / \mathrm{kg} / \mathrm{h} \text { for } \geq \\
12 \text { hours }\end{array}$ \\
\hline Failure & $\begin{array}{l}<0.3 \mathrm{~mL} / \mathrm{kg} / \mathrm{h} \text { for }>24 \\
\text { hours or anuria for } 12 \\
\text { hours }\end{array}$ & Stage 3 & $\begin{array}{l}<0.3 \mathrm{~mL} / \mathrm{kg} / \mathrm{h} \text { for }>24 \\
\text { hours or anuria for } 12 \\
\text { hours }\end{array}$ & Stage 3 & $\begin{array}{l}<0.3 \mathrm{~mL} / \mathrm{kg} / \mathrm{h} \text { for } \geq \\
24 \text { hours or anuria for } \\
\geq 12 \text { hours }\end{array}$ \\
\hline
\end{tabular}

Table 1: Definitions and staging of acute kidney injury. RIFLE: Risk, injury, failure, loss, end-stage renal disease, AKIN: Acute kidney injury network, KDIGO: Kidney disease - improving global outcome, mL: millilitre, kg: kilogram, eGFR: estimated glomerular filtration rate, ESRD: End-stage renal disease, RRT: Renal replacement therapy. $*=$ Serum creatinine changes $\geq 1.5$ times baseline within 7 days. $* *=$ Serum creatinine increases $\geq 26.5 \operatorname{micro}(\mu) \mathrm{mol} / \mathrm{L}$ within a 48 -hour time period. 


\subsubsection{Incidence}

The incidence of AKI varies across studies depending on the populations considered and the definitions used [91]. The occurrence of AKI in general ICU patients is reported to be 10-70\% [6], about one-third experiences AKI within 24 hours [8], and approximately twothirds develops AKI during ICU stay [92]. The most common causes of AKI are sepsis, major cardiac-, vascular- or acute abdominal surgery [5]. Approximately $5 \%$ of the general ICU patients are treated with RRT due to AKI [5]. Furthermore, the incidence of severe AKI necessitating RRT has increased over the last decades [93-95], and this constitutes a major burden of disease [96].

\subsubsection{Risk factors}

Data on causal relationship between assumed risk factor and AKI are lacking, while associations are more apparent. Multiple kidney insults, rather than one single factor, are often necessary to instigate AKI [97]. The primary disease process initiating AKI is often remote from the kidneys, being part of multiple organ failure [98]. Chronic and often unalterable risk factors for AKI are advanced age, diabetes mellitus, hypertension, congestive heart failure and CKD, while acute potentially avoidable risk factors are hypovolaemia, hypotension, hypoperfusion and/or exposure to known nephrotoxic drugs (Table 2).

Trauma patients are usually young and few have established risk factors for AKI [51]. However, they are predisposed to hypovolaemia, hypotension and hypoperfusion due to acute severe bleeding. Rhabdomyolysis may be present, and use of intravenous iodinated radiocontrast media may promote further kidney injury [51]. Although only a minority of trauma patients have direct injuries to the kidney and/or their vessels [99, 100], some might have elevated intra-abdominal pressure or urinary obstruction adversely affecting the kidney function $[101,102]$. In contrast to trauma patients, CA patients often are middle-aged or 
elderly with a high pre-arrest prevalence of diabetes mellitus, hypertension, congestive heart failure and CKD $[81,85]$. These patients also have acute risk factors due to prolonged systemic hypoperfusion, post-arrest cardiogenic shock and use of intravenous contrast media $[81,85]$. Both trauma- and CA patients are susceptible to a pro-inflammatory state with increased risk of severe sepsis that is considered to be a major contributor to AKI in the ICU [5].

Table 2: Nephrotoxic drugs

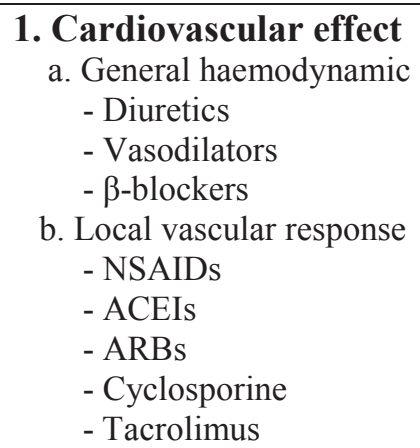

\section{Other nephrotoxins}

- Heavy metals

- Plant extracts

$\begin{array}{cc}\text { 3. Direct tubular effect } & \text { 4. Immunologic activation } \\ \text { a. Proximal tubuli } & \text { a. Acute interstitial nephritis } \\ \text { - Aminoglycosides } & \text { - } \beta \text {-lactam antibiotics } \\ \text { - Cisplatin } & \text { - Vancomycin } \\ \text { - Amphotericin B } & \text { - Rifampicin } \\ \text { - Radiocontrast media } & \text { - Sulphonamides } \\ \text { - Immunoglobulins } & \text { - Ciprofloxacin } \\ \text { - Mannitol } & \text { - NSAIDs } \\ \text { b. Distal tubuli } & \text { - Ranitidine } \\ \text { - NSAIDs } & \text { - Cimetidine } \\ \text { - Lithium } & \text { - Furosemide } \\ \text { - ACEIs } & \text { - Thiazides } \\ \text { - Cyclosporine } & \text { - Phenytoin } \\ \text { - Cyclophosphamide } & \text { b. Acute glomerulonephritis } \\ \text { - Amphotericin B } & \text { - NSAIDs } \\ \text { c. Tubular obstruction } & \text { - Heroin } \\ \text { - Sulphonamides } & \text { - Gold } \\ \text { - Methotrexate } & \text { - Penicillamin } \\ \text { - Acyclovir } & \\ \text { - Diethylene glycol } & \\ \text { - Triamterene } & \end{array}$

Table 2: Overview of nephrotoxic drugs classified based on the mechanisms behind toxic effects. NSAID: Non-steroid anti-inflammatory drug, ACEI: Angiotensin converting enzyme inhibitor. ARB: Angiotensin II receptor blocker. 


\subsubsection{Pathophysiology}

The pathophysiology of AKI is complex and not fully understood. Much focus has previously been on observational studies in humans, concentrating upon systemic effects of AKI, and kidney organ structural- and functional alterations. The classical concept of acute tubular necrosis (ATN) has been challenge by current knowledge emerging a widened understanding of the disease process. AKI research has lately been extended to include interventional studies in animals, assessing structural and functional alterations on organ- and cellular level. These new areas of research might give new insight into the complex pathophysiology of AKI, and ultimately lead to better patient care [103].

In AKI there is often a combination of different pathophysiological mechanisms involved, commonly classified as pre-renal, renal and post-renal (Table 3) [103].

Table 3: Pathophysiological mechanisms involved in acute kidney injury

\begin{tabular}{llll}
\hline & Pre-renal & Renal & Post-renal \\
\hline Occurrence & $25-60 \%$ & $35-70 \%$ & $5-20 \%$ \\
Causes & Decreased renal perfusion & Damage to the four major & Obstruction of the \\
& pressure & structures of the kidneys & urinary tract \\
Clinical & - Reduced blood volume, & - Tubular damage might be & - Various clinical \\
conditions & blood pressure and/or & ischemic and/or toxic & conditions such as \\
& blood flow & - Glomerular damage may & prostate or \\
& & occur in severe acute & gynaecological cancer, \\
& glomerulonephritis $(\mathrm{GN})$ & urethral stones or \\
& retroperitoneal fibrosis \\
& - Interstitial damage may & \\
& result from acute & \\
& interstitial nephritis & \\
& - Vascular damage to the & \\
& intra-renal vessels may & \\
& reduce renal perfusion & \\
\hline
\end{tabular}

Table 3: Overview of the pathophysiological mechanism involved in acute kidney injury.

Although limited data are available in trauma- and CA patients, we may assume that pre-renal mechanism are involved, due to bleeding in trauma patients and tissue ischemia and postresuscitation shock in CA patients. The renal component consisting mainly of ATN may also 
contribute, while post-renal AKI is less likely. All-over, the pathophysiology of AKI includes a wide range of anatomical and physiological alterations at systemic-, organ- and/or cellular level (Table 4) [103].

Table 4: Anatomical and physiological alterations in acute kidney injury

\begin{tabular}{|c|c|c|c|}
\hline & Systemic effects & Organ effects & Cellular effects \\
\hline $\begin{array}{l}\text { Probable } \\
\text { causes }\end{array}$ & $\begin{array}{l}\text { Kidney effects of } \\
\text { systemic disease and } \\
\text { vice versa }\end{array}$ & $\begin{array}{l}\text { Direct effects on the main } \\
\text { structures of the kidneys }\end{array}$ & $\begin{array}{l}\text { Cellular effects in the } \\
\text { kidneys }\end{array}$ \\
\hline $\begin{array}{l}\text { Suggested } \\
\text { mediators of } \\
\text { effects }\end{array}$ & $\begin{array}{l}\text { - Part of systemic } \\
\text { inflammatory response } \\
\text { syndrome (SIRS) with } \\
\text { release of pro- } \\
\text { inflammatory } \\
\text { mediators, extravasation } \\
\text { of leucocytes, increased } \\
\text { oxidative stress and ion } \\
\text { channel dysfunction } \\
\text { - Part of multiple organ } \\
\text { failure } \\
\text { - Part of cardio-renal } \\
\text { syndrome }\end{array}$ & $\begin{array}{l}\text { - Tubuli might be obstructed. } \\
\text { Tubular cells may lose their } \\
\text { polarity, suffer cytoskeletal } \\
\text { breakdown, detach from } \\
\text { their basement membranes } \\
\text { and have altered } \mathrm{Na}^{+} / \mathrm{K}^{+}- \\
\text {Adenosinetriphosphatase } \\
\text { (ATPase) function } \\
\text { - Altered glomerular vascular } \\
\text { resistance and filtration } \\
\text { barrier } \\
\text { - Interstitial inflammation } \\
\text { - Increased vascular } \\
\text { permeability, formation of } \\
\text { microthrombi, and } \\
\text { dysregulation of the intra- } \\
\text { renal blood flow }\end{array}$ & $\begin{array}{l}\text { - Pro-inflammatory } \\
\text { response in the kidneys } \\
\text { with release of } \\
\text { pro-inflammatory } \\
\text { mediators and activation } \\
\text { of the compliment system } \\
\text { - Impaired cellular } \\
\text { energetics with formation } \\
\text { of reactive oxygen species } \\
\text { (ROS) and reduced } \\
\text { antioxidant defence } \\
\text { - Dysregulation of cell } \\
\text { cycle with activation of } \\
\text { caspases and reduced } \\
\text { repair and regeneration } \\
\text { capacity } \\
\text { - Genetic predisposing }\end{array}$ \\
\hline
\end{tabular}

Table 4: Overview of purposed anatomical and physiological alterations in acute kidney injury.

AKI is part of a systemic pro-inflammatory process that may engender distant organ injury to the lungs, heart, liver, brain, gastrointestinal tract and bone marrow [12, 98, 104]. Heart disease and kidney disease often coexists [105], and one illness may adversely affect the other, termed the cardio-renal syndrome [106]. AKI patients may experience an early onset of multiple organ failure with related several fold increase in mortality [9, 107, 108]. Animal models suggest several mechanisms behind this pro-inflammatory state with distant organ injury in AKI (Table 5) [98, 109]. It is evident that AKI often is a part of multiple organ failure in trauma- and CA patients, mainly related to a pro-inflammatory state after trauma [110-112] and circulatory shock after CA [81, 85]. 
AKI may influence different renal structures, i.e. tubuli, glomeruli, interstitium and blood vessels. The tubular cells may lose their polarity, suffer cytoskeletal breakdown, and become detached from the basement membrane [113]. Desquamated cells may obstruct tubuli [114]. Evidence points to functional alterations in sodium reabsorption in the tubular $\mathrm{Na}^{+} / \mathrm{K}^{+}$Adenosinetriphosphatase (ATPase) causing impaired sodium reabsorption [115]. Anatomical glomerular injury is modest in AKI patients despite loss of kidney function [20, 21]. The decline in glomerular filtration rate (GFR) might therefore be due to functional alterations. Indeed, it seems that increased sympathetic activity in sepsis might alter pre- and postglomerular vascular resistance and thereby influence GFR [116]. The glomerular filtration barrier may also be altered in AKI [117]. Another pro-inflammatory mechanism may be overexpression of toll-like receptor (TLR) 2 in glomerular endothelial cells [118]. Interstitial injury in AKI is a result of a pro-inflammatory state leading to vasodilatation, increased vascular permeability and extravasation of leucocytes into the kidney interstitium [119]. The characteristic interstitial infiltrates are mostly composed of lymphocytes, macrophages, eosinophils and plasma cells with rapid transformation into areas of interstitial fibrosis [120]. Changes in the endothelium with increased vascular permeability and formation of microthrombi may lead to dysregulation of the intra-renal blood flow [103, 121]. Solid data are lacking with respect to how intra-renal mechanisms may contribute to AKI in humans. At least in septic patients, the concept of tubular ischemia resulting in ATN has been challenged [4].

There is a multitude of experimental research at cellular- and molecular levels suggesting possible players in the development of AKI. A pro-inflammatory response is observed with release of a myriad of mediators that promote inflammation from the leucocytes (interleukin (IL)-1, IL-8, eicosanoids and others) and the tubular epithelial cells (tumour necrosis factor (TNF)- $\alpha$, IL-1, IL-6, Il-8 and others) [103], and this is further 
enhanced by uncontrolled TLRs signalling and activation of the compliment system [103]. The outer renal medulla is sensitive to depletion of energy substrate and impaired mitochondrial activity, and this may be seen in AKI [103]. Furthermore, the formation of reactive oxygen species (ROS) might play a significant role in the genesis of AKI, and possibly also a reduced antioxidant defence mechanism [103]. Dysregulation of cell cycle has been observed in multiple models of AKI, as well as activation of caspases, i.e. enzymes playing an essential role as primary initiators of cell death [103]. Reduced repair and regeneration capacity have been observed in older animals [103], which may lead to chronic reduced function and thereby predispose for development of CKD [103]. Finally, genetic variation has been discussed in relation to AKI development, although no clear evidence of such a genetic predisposing has been found $[122,123]$. The importance of these cellular mechanisms possibly contributing to AKI would need to be evaluated in humans. Excessive release of pro-inflammatory mediators $[111,124]$ in addition to increased formation of ROS [125] might be central sources of AKI in trauma- and CA patients.

\subsubsection{Prophylaxis}

A lot of research has been done on prophylaxis against AKI in different patients cohorts, and numerous interventions have been tested [126-135]. However, preventive strategies have so far mostly been disappointing [136]. Based on expert opinion, some general prophylactic measures have been advocated for AKI in ICU patients [137]:

- To identify high risk patients and follow their kidney function closely

- To avoid hypovolaemia, hypotension and/or hypoperfusion

- To be cautious in the use of nephrotoxic substances

- To ensure that the urinary tract is not obstructed 
Special attention has been on contrast-induced acute kidney injury (CI-AKI), the most common iatrogenic cause of AKI after intravenous iodinated contrast media administration [126]. These agents may induce renal vasoconstriction, increase oxidative stress, and have direct tubular toxicity. Currently recommended measures to prevent CI-AKI is intravascular volume expansion with either isotonic saline- or sodium bicarbonate solutions [126].

Toxic substances from necrotic muscular cells observed in rhabdomyolysis are considered to be important contributors to AKI after trauma. Myoglobin may cause AKI through renal vasoconstriction, formation of intratubular casts, and the direct toxicity to tubular cells [138]. New research has also revealed that myoglobin increases oxidative stress, inflammation, endothelial dysfunction, vasoconstriction, and apoptosis [139]. Early and aggressive fluid resuscitation to increase urine output as in forced diuresis is agreed on as the main intervention for preventing AKI [138]. New drugs that target the harmful effects of myoglobin have been recently developed, and some have been proven to be successful in animal models of AKI due to rhabdomyolysis [139].

Unfortunately, no single preventive cure against AKI exists for trauma- and CA patients, but clinicians should still use the general recommendations mentioned above.

\subsubsection{Diagnosis}

AKI is usually diagnosed based on reduced urine output and/or elevated kidney markers in blood samples. A more comprehensive examination may be required to separate AKI from $\mathrm{CKD}$, and to find potentially curable causes of AKI. Clinicians should explore known risk factors for AKI (age, hypertension, diabetes mellitus etc.), the duration of disease (CKD has duration above 3 months) and presence of kidney specific symptoms (weight gain, fatigue, nausea and pruritus). The physical examination should include clinical signs of cerebral 
dysfunction (encephalopathy), cardiovascular dysfunction (tachycardia, hypotension and pericarditis) and fluid overload (peripheral oedema and pulmonary congestion). Blood sample analyses may detect retention of metabolic waste products (high creatinine and urea), electrolyte abnormalities (high potassium $\left(\mathrm{K}^{+}\right)$and variable other electrolyte abnormalities), acid/base-abnormalities (low Pondus hydrogenii $(\mathrm{pH})$, bicarbonate $\left(\mathrm{HCO}_{3}{ }^{-}\right)$and base excess (BE)) and biomarkers of rhabdomyolysis (high creatine kinase (CK) and myoglobin). Serum creatinine measurements have several limitations, as they are dependent on muscular mass, do not detect rapid changes in GFR, might be affected by conditions remote from the kidneys (dietary intake and rhabdomyolysis), and may be falsely measured using colorimetric methods (due to pseudocreatinines such as cephalosporins and others) [140]. Laboratories often provide an eGFR based on the measured serum creatinine concentration $\left(\mathrm{S}_{\mathrm{cr}}\right)$ put into mathematical formulas, such as eGFR modification of diet in renal disease (MDRD) formula: $\operatorname{eGFR}\left(\mathrm{mL} / \mathrm{min} / 1.73\right.$ square meter $\left.\left(\mathrm{m}^{2}\right)\right)=175 \times\left(\mathrm{S}_{\mathrm{cr}}\right)^{-1.154} \times(\mathrm{Age})^{-0.203} \times(0.742$ if female $) \times(1.212$ if African $)$

Although creatinine- and eGFR levels are validated markers of kidney disease recommended to be used in CKD, they are of limited value in AKI due to lack of a steady-state situation [141]. Some therefore recommend to calculate GFR as urine creatinine clearance $\left(\mathrm{C}_{\mathrm{Cr}}\right)$ based on the creatinine concentration in urine $\left(\mathrm{U}_{\mathrm{Cr}}\right)$, urine flow rate $(\mathrm{Vdt})$, and plasma creatinine $\left(\mathrm{P}_{\mathrm{Cr}}\right)[141]:$

$\mathrm{C}_{\mathrm{Cr}}(\mathrm{mL} /$ minute(min) $)=\left[\mathrm{U}_{\mathrm{Cr}} \times \mathbf{V d t}\right] / \mathbf{P}_{\mathrm{Cr}}$

Radiographic imaging using Doppler ultrasound of the urinary tract should be done in AKI to exclude urinary obstruction. Additional analyses including chemical content of urine, urine dipstick analysis, microscopic evaluation of the urine sediment, serological tests and renal biopsy have limited value in AKI. 
Several biomarkers have been proposed for early detection of AKI. An ideal biomarker should optimally have a reasonable sampling window, be easy to obtain, rapid to measure, change expression early during the disease process, provide high sensitivity and specificity, and be cost effective [38]. Current AKI biomarkers have several limitations as they are sensitive to sampling time, background noise, heterogeneity of patients and heterogeneity of disease processes. Additionally, the biomarkers have variable ability to discriminate between causes of AKI and to predict patient outcome.

An overview of the most promising AKI biomarkers is provided in Table 5. In order to improve biomarker performance, some advocate the use of several biomarkers [142], or that biomarkers should be combined with clinical patient data [143].

\section{Table 5: Biomarkers of acute kidney injury}

\begin{tabular}{|c|c|c|c|c|c|}
\hline $\begin{array}{l}\text { Biomarker } \\
\text { abbreviation }\end{array}$ & $\begin{array}{l}\text { Biomarker full } \\
\text { name }\end{array}$ & $\begin{array}{l}\text { Molecular } \\
\text { size (kDa) }\end{array}$ & $\begin{array}{l}\text { Source } \\
\text { tested }\end{array}$ & $\begin{array}{l}\text { Site of kidney } \\
\text { expression }\end{array}$ & $\begin{array}{l}\text { Biomarker } \\
\text { rationale }\end{array}$ \\
\hline Cystatin $\mathrm{C}$ & Cystatin C & 13 & $\begin{array}{l}\text { Urine } \\
\text { and } \\
\text { serum }\end{array}$ & All nucleated cells & $\begin{array}{l}\text { Glomerular } \\
\text { filtration marker }\end{array}$ \\
\hline NGAL & $\begin{array}{l}\text { Neutrophil } \\
\text { gelatinase- } \\
\text { associated } \\
\text { lipocalin }\end{array}$ & 25 & $\begin{array}{l}\text { Urine } \\
\text { and } \\
\text { serum }\end{array}$ & $\begin{array}{l}\text { Proximal and distal } \\
\text { tubular neutrophils } \\
\text { Epithelial cells }\end{array}$ & $\begin{array}{l}\text { Inflammatory } \\
\text { marker }\end{array}$ \\
\hline KIM-1 & $\begin{array}{l}\text { Kidney injury } \\
\text { molecule } 1\end{array}$ & 38.7 & Urine & $\begin{array}{l}\text { Proximal tubular } \\
\text { cells }\end{array}$ & Cell injury marker \\
\hline IL-18 & Interleukin 18 & 22 & $\begin{array}{l}\text { Urine } \\
\text { and } \\
\text { serum }\end{array}$ & $\begin{array}{l}\text { Proximal tubular } \\
\text { cells and leucocytes }\end{array}$ & $\begin{array}{l}\text { Inflammatory } \\
\text { marker }\end{array}$ \\
\hline L-FABP & $\begin{array}{l}\text { Liver-type fatty } \\
\text { acid-binding } \\
\text { protein }\end{array}$ & 14 & Urine & $\begin{array}{l}\text { Proximal tubular } \\
\text { cells }\end{array}$ & Cell injury marker \\
\hline TIMP-2 & $\begin{array}{l}\text { Tissue inhibitor of } \\
\text { metalloproteinase } \\
2\end{array}$ & 21 & Urine & Tubular cells & Cell cycle marker \\
\hline IGFBP7 & $\begin{array}{l}\text { Insulin-like growth } \\
\text { factor-binding } \\
\text { protein } 7\end{array}$ & 29 & Urine & $\begin{array}{l}\text { Endothelial, } \\
\text { vascular, epithelial } \\
\text { cells and others }\end{array}$ & Cell cycle marker \\
\hline Angiotensinogen & Angiotensinogen & 52 & Urine & $\begin{array}{l}\text { Kidney } \\
\text { vasoconstrictor }\end{array}$ & $\begin{array}{l}\text { Renin-angiotensin } \\
\text { system activation } \\
\text { marker }\end{array}$ \\
\hline
\end{tabular}

Table 5: Overview of biomarkers for acute kidney injury tested in intensive care unit patients. kDa: Kilo Dalton. 
There are no specific recommendations for AKI diagnosis in trauma- and CA patients, but these patient groups may benefit from close monitoring of $\mathrm{CK}$ and/or myoglobin levels in blood in order to detect rhabdomyolysis [144]. Close collaboration with nephrologists should be encouraged, especially in cases with uncertain cause of the AKI [145].

\subsubsection{General supportive treatment}

It is vital to identify and treat the underlying condition causing AKI, as for instance sepsis or rhabdomyolysis. General supportive care of patients should be optimized including appropriate use of fluids, vasopressor and glycaemic control [25]. The kidney function should be closely monitored with frequent blood sampling and urine output measurements. Hypovolaemia, hypotension, hypoperfusion, use of nephrotoxic drugs and urinary tract obstruction should be avoided. Symptomatic treatment of AKI complications, such as fluid overload, hyperkalaemia and acidosis, may be used alone or in combination with RRT [25].

\subsubsection{Renal replacement therapy}

The use of RRT varies substantially across the world [146-148] despite the fact that international guidelines are developed [25]. In AKI, the primary aim of RRT is to temporary replace kidney function with elimination of fluid and metabolic waste products from the body. Secondary aims of dialysis therapy are to minimize complications of the disease process and the treatment, and finally to optimize patient comfort.

There is no consensus on when to initiate RRT, but international guidelines recommend that RRT should be emergently started when life-threatening changes in fluid-, electrolyte- and/or acid-base balance exist [25]. These guidelines also recommend that the decision on when to initiate RRT should be considered in a broad clinical context considering more than kidney function parameters [25]. It is uncertain whether early initiation of RRT 
may have a beneficial impact on patient outcome compared to late initiation [30, 149-152], and the lack of a uniform definition of early and late initiation makes comparison of studies difficult.

The most commonly used RRT modality in the developed world has changed over years from peritoneal dialysis (PD), via intermittent haemodialysis (IHD), to various forms of continuous renal replacement therapy (CRRT). Although mortality rates in patients treated with IHD and CRRT are similar [153-155], haemodynamic stability is better preserved in CRRT [153]. It is uncertain whether the choice of dialysis modus affects the rate of chronic dialysis dependency $[156,157]$. There are additionally different CRRT modalities such as continuous veno-venous haemodialysis (CVVHD), continuous veno-venous haemofiltration (CVVHF) and continuous veno-venous haemodiafiltration (CVVHDF) associated with similar patient outcomes $[158,159]$. IHD and CRRT are considered complimentary therapies in recent treatment guidelines of AKI, but CRRT is recommended in haemodynamic unstable patients and in cases of increased intracerebral pressure or generalized brain oedema [25].

The optimal dose of RRT is uncertain, and in CRRT there is a discrepancy between prescribed dose and delivered dose due to interruptions during treatment [160]. Higher intensity RRT does not reduce mortality rates or improve renal recovery compared to conventional doses $[34,161,162]$. The currently recommended delivered doses in AKI is for IHD 3.9 Kt/V (dialyzer clearance of urea $(\mathrm{K})$ multiplied by time $(\mathrm{t})$ divided by the volume of distribution of urea (V)) per week and for CRRT 20-25 mL/kg/h [25], with adjustment during treatment in order to achieve goals of electrolyte-, acid-base-, solute- and fluid balance.

Treatment guidelines for AKI also include recommendations for the equipment used, including haemodialysis catheters, haemodialysis membranes, dialysate- and replacement fluids in addition to the use of anticoagulation [25]. Discontinuation of RRT in AKI should be 
considered when dialysis is no longer required because kidney function has recovered adequately or in cases of futile treatment [25].

Withholding or withdrawing RRT is a complex decision that sometimes is necessary in order to reduce the burden of futile treatment to patients, relatives and the healthcare system. Withholding or withdrawing RRT depends on many interacting factors, which are unique for each patient and their families. An evidence-based guideline with specific recommendations has been available, however is infrequently employed to help decision making in clinical practice [163].

In a recent study of trauma patients with severe injuries, AKI with need of RRT occurred in $5 \%$ of the patients [164]. In a systematic review and meta-analysis of patients with severe burn injuries, RRT was used in $3 \%$ of the total population, and in $30 \%$ of patients with AKI [28]. In another meta-analysis of CA victims, on average $14 \%$ of the patients were treated with RRT, but the frequency ranged from $4 \%$ to $33 \%$ in the different studies [85]. The trauma patients might need adjustment of CRRT due to extensive tissue necrosis with rise in metabolic waste products, and frequent interruptions during treatment. Important indications for RRT in trauma patients might be hypervolaemia due to initial fluid resuscitation and hyperkalaemia due to massive tissue damage. Withholding or withdrawing RRT might important issues in CA patients with lack of early guidelines to be used in the ICU. Rhabdomyolysis frequently occur in both patient groups, but how this affects the use of RRT remains unsettled [138].

The costs of RRT are substantial including expenses due to nurse staffing, anticoagulation, extracorporeal circuits in addition to dialysate- and replacement fluids [165]. In undeveloped countries patients still die because dialysis treatment is unavailable, but the use of PD, which is the cheapest and easiest method, is saving lives in many parts of the world. 


\subsubsection{Outcome}

AKI in ICU patients is associated with an unfavourable survival rate that is worsened with the severity of the disease $[8,92]$. Mortality seem to be closely linked to the development of multiple organ failure, and survival is dependent on the recovery of organ functions [166]. Despite recent advances in patient care, the acute mortality in severe cases with need of RRT is still around $50 \%[167,168]$. There is also increasing evidence showing that AKI in the ICU is associated with reduced long-time survival of patients $[18,19]$. Although data are limited, similar mortality findings have been observed in CA patients, and to some extent in trauma patients $[56,61,85]$.

Data from general ICU patients show that few AKI victims become dependent on chronic RRT [18]. However, AKI is associated with increased risk of CKD as compared to an ICU control population without AKI [19]. Further, development of CKD is dependent on premorbid kidney function, cause of AKI, as well as presence of co-morbidities [168]. There is increasing evidence that AKI is especially harmful in CKD patients, leading to a worsening of the CKD [169]. Furthermore, AKI is also associated with later on increased risk for cardiovascular disease and congestive heart failure [170]. How this is in the subgroups of trauma- and CA patients remains unclear, sparse data in trauma patients show that few patients with post-traumatic AKI become chronic RRT dependent $[10,56]$.

There are some data available from general ICU patients revealing that RRT has an overall good acceptability, as over $90 \%$ of patients indicated that they would undergo the same treatment again $[18,171]$. Unfortunately, there are no such available data in trauma- and CA patients, but there is no reason to believe that these groups should be different from other ICU patients with respect to RRT acceptability. 


\section{Aims and research questions}

The general aim of this thesis was to investigate AKI in two heterogeneous subgroups of ICU patients that are modestly studied, i.e. trauma- and OHCA patients. We had no specific hypotheses in our exploratory studies. The specific research aims and questions were:

1. To explore the occurrence of AKI necessitating RRT in trauma patients, and describe mortality and renal recovery in this patient group.

2. To evaluate the quality of RRT in trauma patients with AKI, focusing upon daily duration of CRRT, reasons for temporary interruptions and uraemic control.

3. To evaluate the occurrence of kidney disease in OHCA victims, and to explore the association between kidney disease and patient outcome.

4. To examine the utility of urine AKI biomarkers in OHCA victims, and their ability to predict AKI, mortality and/or neurological outcome. 


\section{Materials and methods}

\subsection{Study setting and design}

This thesis includes four observational studies from Oslo University Hospital Ullevål (OUHU). OUHU is a community hospital for approximately 200.000 people and a regional hospital for 1.4 million people in Norway, with around 45.000 admissions per year. All four studies have single-centre observational cohort design; the trauma studies are retrospective (Paper 1 and II), whereas the cardiac arrest studies are prospective (Paper III and IV). An overview of studies included in this thesis is provided in Table 6.

\subsection{Study population}

In the trauma studies (Paper I and II) adult ( $\geq 18$ years) trauma patients were included if they developed AKI treated with RRT. Patients with CKD, and those who died within 24 hours, were excluded (Paper I and II). In the analysis of dialysis quality, patients with CRRT lasting less than 24 hours were excluded (Paper II).

In the CA studies (Paper III and IV) adult ( $\geq 18$ years) comatose (Glasgow Coma Scale (GCS) $\leq 8$ at admission) OHCA patients with ROSC (Paper III and IV) admitted to ICU treated with TTM were included in the Norwegian cardiorespiratory arrest (NORCAST) study registered at Clinicaltrials.gov (National clinical trial (NCT) number NCT01239420). The primary aim of this study was to assess predictors of outcome after OHCA (data yet not published). The NORCAST study had many exclusion criteria (dead before ICU admittance, in-hospital CA at another hospital, subarachnoid haemorrhage, other cause of coma, CPR $<5$ minutes or spontaneous awakening, head trauma, age $<18$ years, intracerebral haemorrhage, unknown patient identity, transferred to another hospital, abdominal bleeding or previously included). In our a priori planned sub-studies on AKI patients we excluded those who died within 24 hours of ICU stay or for some reason did not receive active treatment 
Table 6: Thesis overview

\begin{tabular}{|c|c|c|c|c|}
\hline & Paper I & Paper II & Paper III & Paper IV \\
\hline Study design & $\begin{array}{l}\text { Retrospective cohort } \\
\text { study }\end{array}$ & $\begin{array}{l}\text { Retrospective cohort } \\
\text { study }\end{array}$ & $\begin{array}{l}\text { Prospective } \\
\text { cohort study }\end{array}$ & $\begin{array}{l}\text { Prospective } \\
\text { cohort study }\end{array}$ \\
\hline Study site & $\begin{array}{l}\text { Oslo University } \\
\text { Hospital Ullevål }\end{array}$ & $\begin{array}{l}\text { Oslo University } \\
\text { Hospital Ullevål }\end{array}$ & $\begin{array}{l}\text { Oslo University } \\
\text { Hospital Ullevål }\end{array}$ & $\begin{array}{l}\text { Oslo University } \\
\text { Hospital Ullevål }\end{array}$ \\
\hline Study period & 1996-2007 & 1997-2006 & $2010-2014$ & $2010-2014$ \\
\hline Data sources & $\begin{array}{l}\text { Hospital registries } \\
\text { Statistics Norway } \\
\text { Norwegian Renal } \\
\text { Registry }\end{array}$ & Hospital registries & Hospital registries & Hospital registries \\
\hline Population & $\begin{array}{l}\text { Trauma patients } \\
\text { admitted with AKI } \\
\text { and RRT } \\
(\mathrm{n}=42)\end{array}$ & $\begin{array}{l}\text { Trauma patients with } \\
\text { AKI and CRRT } \\
\text { more than } 24 \text { hours } \\
(n=36)\end{array}$ & $\begin{array}{l}\text { Admitted OHCA } \\
\text { patients }(n=245)\end{array}$ & $\begin{array}{l}\text { Admitted OHCA } \\
\text { patients with } \\
\text { collected urine } \\
\text { samples }(n=195)\end{array}$ \\
\hline Intervention & Standard care & Standard care & Standard care & Standard care \\
\hline Comparison & $\begin{array}{l}\text { Epidemiological } \\
\text { study of AKI with } \\
\text { RRT }\end{array}$ & $\begin{array}{l}\text { Study of CRRT } \\
\text { quality }\end{array}$ & $\begin{array}{l}\text { Epidemiological study } \\
\text { of CKD and AKI }\end{array}$ & $\begin{array}{l}\text { Diagnostic and } \\
\text { prognostic utility of } \\
\text { AKI biomarkers }\end{array}$ \\
\hline Outcomes & $\begin{array}{l}\text { Occurrence of AKI } \\
\text { with RRT } \\
\text { Mortality } \\
\text { Chronic RRT } \\
\text { dependency }\end{array}$ & $\begin{array}{l}\text { Daily duration of } \\
\text { CRRT and impact } \\
\text { on uraemic control } \\
\text { Reasons for CRRT } \\
\text { interruption }\end{array}$ & $\begin{array}{l}\text { Occurrence of CKD } \\
\text { and AKI } \\
\text { Mortality } \\
\text { Neurological outcome }\end{array}$ & $\begin{array}{l}\text { AKI biomarkers } \\
\text { ability to predict } \\
\text { AKI, mortality and } \\
\text { neurological } \\
\text { outcome }\end{array}$ \\
\hline $\begin{array}{l}\text { Biochemical } \\
\text { analyses }\end{array}$ & $\begin{array}{l}\text { Routine analyses in } \\
\text { blood samples, no } \\
\text { supplemental } \\
\text { analysis }\end{array}$ & $\begin{array}{l}\text { Routine analyses in } \\
\text { blood samples, no } \\
\text { supplemental } \\
\text { analysis }\end{array}$ & $\begin{array}{l}\text { Routine analyses in } \\
\text { blood samples, no } \\
\text { supplemental analysis }\end{array}$ & $\begin{array}{l}\text { Routine analyses in } \\
\text { blood samples. } \\
\text { Additional urine } \\
\text { biomarkers at } \\
\text { admission and day } \\
\text { three: Cystatin C, } \\
\text { NGAL and } \\
\text { [TIMP-2]·[IGFBP7] }\end{array}$ \\
\hline $\begin{array}{l}\text { Statistical } \\
\text { analyses }\end{array}$ & $\begin{array}{l}\text { Pearson's chi-square } \\
\text { test } \\
\text { Mann-Whitney U } \\
\text { test } \\
\text { Logistic regression } \\
\text { analysis }\end{array}$ & $\begin{array}{l}\text { Pearson's chi-square } \\
\text { test } \\
\text { Mann-Whitney U } \\
\text { test } \\
\text { Linear regression } \\
\text { analysis }\end{array}$ & $\begin{array}{l}\text { Pearson's chi-square } \\
\text { test } \\
\text { Fisher's exact test } \\
\text { Mann-Whitney U test } \\
\text { Independent sample T- } \\
\text { test } \\
\text { Kaplan-Meier log rank } \\
\text { test } \\
\text { Logistic regression } \\
\text { analysis }\end{array}$ & $\begin{array}{l}\text { Pearson's chi- } \\
\text { square test } \\
\text { Fisher's exact test } \\
\text { Logistic regression } \\
\text { analysis } \\
\text { Receiver operating } \\
\text { characteristics } \\
\text { analysis }\end{array}$ \\
\hline $\begin{array}{l}\text { External } \\
\text { approvals }\end{array}$ & $\begin{array}{l}\text { Regional ethics } \\
\text { committee } \\
\text { Norwegian Data } \\
\text { Inspectorate } \\
\text { Norwegian } \\
\text { Directorate for } \\
\text { Health and Social } \\
\text { Affairs }\end{array}$ & $\begin{array}{l}\text { Regional ethics } \\
\text { committee } \\
\text { Norwegian Data } \\
\text { Inspectorate } \\
\text { Norwegian } \\
\text { Directorate for } \\
\text { Health and Social } \\
\text { Affairs }\end{array}$ & $\begin{array}{l}\text { Regional ethics } \\
\text { committee }\end{array}$ & $\begin{array}{l}\text { Regional ethics } \\
\text { committee }\end{array}$ \\
\hline Registrations & None & None & NCT01239420 & NCT01239420 \\
\hline
\end{tabular}

Table 6: Overview of studies included in this thesis. AKI: Acute kidney injury, RRT: Renal replacement therapy, n: number, CRRT: Continuous renal replacement therapy, OHCA: Out-of-hospital cardiac arrest, CKD: Chronic kidney disease. NGAL: Neutrophil gelatinase-associated lipocalin, TIMP: Tissue inhibitor of metalloproteinase, IGFBP: Insulin-like growth factor-binding protein. NCT: National clinical trial. 
(Paper III and IV). In the analyses of AKI biomarkers, patients without collected urine samples and/or with known CKD were excluded (Paper IV).

\subsection{Ethical considerations and approvals}

The risk of participation in the studies was considered minimal since all studies were observational and patients received standard care.

The trauma studies (Paper I and II) were approved by the Regional Committee for Medical Ethics of Eastern Norway (Approved number REK 1, 408-06170 1.2006.2069). No patient consent was needed for this retrospective register and journal study according to the ethical approval, but written information was sent by postal mail to all included patients. The trauma studies (Paper I and II) were additionally approved by the Norwegian Data Inspectorate (Datatilsynet, reference number 06/1743-7/MOF), the Norwegian Directorate for Health and Social Affairs (Sosial- og helsedirektoratet, reference number 06/2655) and the hospital-based trauma registry (Approval dated 31th October 2007).

The OHCA studies (Paper III and IV) were approved by the Regional Committee for Medical Ethics of South-East Norway (Approval number REK S-O A Ref 2010/1116a). Written informed consent was obtained from the nearest family relative after admission and later from all patients who regained consciousness and were considered competent to give consent within six months. Patients were not considered for inclusion if the nearest family relative opposed it. Relatives were not asked for consent if the patient did not meet the inclusion criteria. Family relatives who were not present at the hospital were contacted by phone and had written study information sent by postal mail. The Regional Committee for Medical Ethics of South-East Norway approved the inclusion of some patients whose relatives were unreachable or failed to return their consent forms. 


\subsection{Study definitions}

The study definitions used in the four papers are:

- Trauma was defined as patients having a trauma diagnosis code according to the International statistical classification of diseases and related health problems (International classification of disease (ICD)-9 and ICD-10), excluding diagnosis codes for late effects of trauma, foreign bodies and complications.

- $O H C A$ was defined as absence of spontaneous respiration in a comatose patient receiving cardiopulmonary resuscitation.

- $R O S C$ was identified as sustained electrical activity on the electrocardiogram, generating a palpable pulse.

- $A K I$ was defined as patients having a diagnose code for acute renal failure, and/or a national procedure code for dialysis in Paper I and II, and as patients having AKI according to a modified version of the KDIGO criteria in Paper III and IV.

- $\quad C K D$ diagnosis was based on a positive medical history of chronic kidney disease.

- $\quad$ RRT was defined as PD, IHD or CRRT (any modality).

- Severity of trauma was assessed by the Revised trauma score (RTS) [172] and the ISS [48].

- Severity of illness was determined by the SAPS II score including 12 physiological variables and three disease-related variables generating a score ranging from 0 to 163 points [44].

- Organ failure assessment was done using the SOFA score assessing the respiratory, cardiovascular, liver, kidney coagulation and neurological systems generating a score ranging from 0 to 24 [45]. Organ failure was defined as a SOFA score $\geq 3$, and multiple organ failure as organ failure of three or more organs. 
- Sepsis was diagnosed according to the criteria from the American college of chest physicians/Society of critical care medicine (ACCP/SCCM) consensus conference [173].

- Renal recovery was defined as independency from RRT at the time of assessment.

- Uraemic control was defined as the percent changes in daily serum urea and creatinine concentrations.

- Neurological outcome was assessed using CPC assessed six months post-arrest, and was classified as good (CPC 1 or 2) or poor (CPC 3-5) neurological outcome (PNO).

- Circulatory shock was defined as systolic blood pressure less than $90 \mathrm{mmHg}$, or a decrease in systolic blood pressure of more than $40 \%$ from baseline, and lasting more than one hour.

- Volume load was characterized as intravenous infusion of more than $500 \mathrm{~mL}$ of any fluid in less than half an hour.

- Inotropic therapy was defined as dopamine and/or dobutamine infusion.

- Vasoactive therapy was defined as norepinephrine and/or epinephrine infusion.

- Rhabdomyolysis: Peak serum CK above 10.000 U/L.

- Urinary tract obstruction was diagnosed based on radiographic descriptions and/or findings during abdominal surgery.

- Fluid overload was defined as a positive fluid balance leading to oxygenation problem (Paper II) or as an indication for RRT if it was mentioned as a reason for initiating RRT (Paper III).

- Hyperkalaemia was defined as serum potassium above $5.0 \mathrm{mmol} / \mathrm{L}$.

- Acidosis was defines as whole blood pH below 7.25.

- Uraemia was defined as serum urea above $30 \mathrm{mmol} / \mathrm{L}$.

- Fluid input was calculated as the sum of any fluids into patients. 
- Fluid output was calculated as the sum of any fluids out of patients.

- Fluid balance was calculated as fluid input minus fluid output (perspiration not included).

\subsection{Data collection}

In Paper I and II, trauma patients with AKI undergoing RRT were identified from diagnosis and procedure codes, and several databases were crosschecked (hospital charts, medical records, trauma registry, intensive care registry and national renal registry) to ensure that no patients were lost. Data were collected from the patients' medical charts and routine biochemical analyses. Additionally, data on chronic RRT dependency (above three months) were obtained from the Norwegian Renal Registry including data from all patients receiving RRT for CRF in Norway. General population data were collected from Statistics Norway in order to calculate population based incidence rates of post-traumatic AKI necessitating RRT in the total population, and also separately in men and women.

In Paper III and IV, OHCA patients were consecutively enrolled using predefined inclusion and exclusion criteria outlined above. Most data were collected from the patients' medical charts, routine biochemical analyses and the hospital-based CA registry including prehospital data. Additional examinations were undertaken according to the aims of the study, including the collection of urine samples at admission and day three for the analyses of AKI biomarkers (outlined below). Moreover, data on six-month outcome (mortality and neurological recovery) were obtained during an extensive post-arrest consultation at OUHU, but the extended follow-up did not include data on kidney function. 


\subsection{Laboratory assays}

The blood sample analyses included in this thesis were obtained from the patients on clinical indications, and no additional samples were collected for research purposes. For all papers (Paper I-IV) the biochemical blood sample analyses were performed at the Department of Medical Biochemistry, OUHU. These samples were analysed by bioengineers blinded for clinical data. The arterial blood gas samples were collected by ICU nurses not blinded for clinical data, and examined in blood gas analysers at the ICU.

For evaluating AKI biomarkers in OHCA patients (Paper IV), spot urine samples were collected from urine catheters at admission ( 0 to 6 hours post arrest) and day three. Samples were stored in a refrigerator up to 72 hours before frozen at $-70^{\circ} \mathrm{C}$. After thawing, samples were centrifuged for five minutes at $20^{\circ} \mathrm{C}$ and 500 relative centrifugation force $(\mathrm{RCF})$, aliquoted and refrozen. Thereafter, the urine samples were re-thawed and identical recentrifuged before they were diluted 1/200 and run in duplicate according to the manufacturers' instructions. Cystatin C and NGAL were quantified using Bio-Plex Pro RBM Human Kidney Toxicity Assays panel 2 on the Bio-Plex 200 system (Bio-Rad Laboratories, Hercules, CA, USA).

The concentrations of TIMP-2 and IGFBP7 were measured using the NephroCheck $^{\mathrm{TM}}$ Test (Astute Medical, San Diego, CA, USA) calculating the product of both biomarker concentrations ([TIMP-2]·[IGFBP7]). A pilot study revealed that the studied biomarkers in urine were stable when stored in a refrigerator up to 72 hours prior to freezing, and when centrifuged after thawing [174]. Based on these results and previous studies $[175,176]$, we assume that our results regarding the AKI biomarkers are valid. 


\subsection{Statistical analyses}

Statistical analyses were performed utilizing Statistical package for social sciences (SPSS) for Windows, version 15.0 (IBM Inc., Chicago, IL, USA) (Paper I and II) and 21.0 (IBM Corp., Armonk, NY, USA) (Paper III and IV). In Paper IV, we also used Stata 14 (StataCorp, College Station, TX, USA) in some of the analyses. In all instances, the level of statistical significance was set at a two-sided $\mathrm{p}<0.05$.

The statistical analyses included in this thesis are briefly described below:

- Pearson's chi-square test (Paper I-IV): Categorical, unpaired data were expressed as number (percent), and compared using Pearson's chi-square test. This test evaluated how likely it was that the observed difference between data sets arose by chance, and this probability was calculated as the p-value.

- Fisher's exact test (Paper III and IV): Categorical, unpaired data with small sample size (expected value below 5) were expressed as number (percent), and compared using Fisher's exact test. This test evaluated how likely it was that the observed difference between data sets arose by chance, and this probability was calculated as the p-value.

- Mann-Whitney U test (Paper I-III): Continuous, independent data with skewed distribution were expressed as median (interquartile range (IQR)), and compared using Mann-Whitney $U$ test. This test evaluated if one population had larger values compared to another population, and this probability was expressed as the p-value.

- Independent sample T-test (Paper III): Continuous, independent data with normal distribution were expressed as mean ( \pm standard deviation $(\mathrm{SD}))$, and compared using independent sample T-test. This test determined if two data sets were statistically significant different from each other, and this probability was expressed as the pvalue. 
- Logistic regression analysis (Paper I, III and IV): Logistic regression analysis measured the relationship between a categorical dependent variable and several independent variables. The test estimated probabilities that the relationship between variables arose by chance using a logistic function, and this probability was expressed as the p-value.

- Linear regression analysis (Paper II): Linear regression analysis was used to calculate the relationship between the continuous, dependent variable and the explanatory, independent variable. The relation between variables was expressed as the correlation coefficient ( $\mathrm{r}$ ), and the $\mathrm{p}$-value of the regression line expressed the probability that the relationship between variables arose by chance.

- Kaplan-Meier survival curve (Paper III): Survival distribution of different populations was compared using Kaplan-Meier survival curve, and tested by the log rank test. This test evaluated how likely it was that the observed mortality in different groups arose by chance, and this probability was calculated as the p-value.

- Identifying independent risk factors (Paper IV): Variables with $\mathrm{p}<0.25$ in the univariate logistic regression analyses were considered candidates for the multivariate model if they had less than $15 \%$ missing data. Independent risk factors were identified using a multivariate logistic regression model and a manual backward stepwise elimination procedure. Multivariate analyses were preceded by estimation of correlation between risk factors. Evaluation of the predictive accuracy of the models was assessed by calibration and discrimination. Calibration was evaluated by the Hosmer and Lemeshow goodness-of-fit test. A statistically non-significant Hosmer and Lemeshow result $(\mathrm{p}>0.05)$ suggests that the model predicts accurately on average. Discrimination was evaluated by analysis of the area under the Receiver operating characteristics (ROC) curve. The ROC plot is as a visual presentation of sensitivity 
versus 1-specificity. The area under the ROC curve (AuROC) is calculated indicating the level of discriminating ability, where 0.5 is considered as no discriminating value, whereas 1.0 indicate perfect discriminating ability. An acceptable discriminatory capability was defined as an AuROC above 0.7 in our study. Chi-square tests for equality of AuROCs were additionally performed to evaluate whether the differences in ROC plots occurred by chance, and this probability was expressed as a p-value.

- Handling of repetitive measurements (Paper II): In cases of repetitive measurements in the same individual, median values calculated for each individual was used to ensure that calculated p-values were not invalidated by dependent data set.

- Handling of missing data (Paper III and IV): Missing data may be handled by different statistical methods. We generally handled the missing data by using only available data, with the exception of the body weight of OHCA patients that were assumed to be $70 \mathrm{~kg}$ in females and $80 \mathrm{~kg}$ in males if unknown.

- $\quad$ Out of range measurements (Paper IV): Some of the measured concentrations were out of range for the assays used in the analyses of AKI biomarkers. In the statistical analyses, measured levels below the lower range were set as 0 , whereas concentrations above the upper range were set as 100.000 . 


\section{Results}

\subsection{Paper I}

The study included 42 adult trauma patients admitted to OUHU between 1996 and 2007 with AKI necessitating RRT. Median age of the patients was 46 years, and $86 \%$ were male. Patients were severely injured with a median ISS 36. RRT were initiated 1-25 days after trauma and lasted for 1-43 days. The mode of RRT was mainly CVVHDF, but some also received CVVHD or PD. Treatment was often switched to IHD after haemodynamic stabilization.

The population based incidence of post-traumatic AKI with RRT was 1.8 (95\% confidence interval (CI) 1.5-2.1) persons per million inhabitants per year. In trauma patients admitted to hospital incidence of AKI necessitating RRT was $0.5 \%$ (95 \% CI 0.3-0.7 \%o), of those treated in ICU $8.3 \%$ (95 \% CI 5.9-10.8 \%). The odds ratio (OR) for post-traumatic AKI requiring RRT was higher in males than females in the general population (OR 5.6, $95 \%$ CI 2.2-14.0) as well as in the trauma patients admitted to hospital (OR 4.4, 95 \% CI 1.9-10.3) and ICU (OR 4.5, 95 \% CI 1.9-10.7). Assessing risk factors for AKI, $71 \%$ received iodinated radiocontrast agents, $41 \%$ had rhabdomyolysis and $12 \%$ had urinary tract obstruction. Mortality was $36 \%$ at three months and $40 \%$ one year after the trauma. Age was a risk factor for death after one year with $57 \%$ (95\% CI 7-109\%) increased risk for each 10 years added. None of the survivors were dialysis-dependent three months or one year after their traumatic event. 
In additional unpublished subgroup analysis, we found that time from trauma to initiation of RRT was similar in patients with and without rhabdomyolysis (median 5.0 days versus 7.5 days, $\mathrm{p}=0.20$, respectively) (Two-tailed Mann-Whitney U test) (Figure 1).

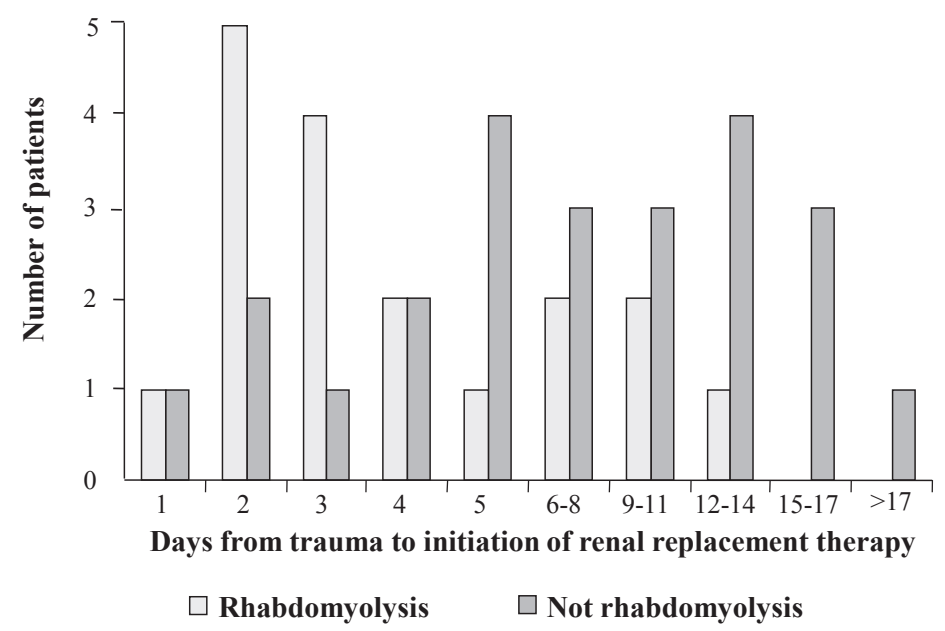

Figure 1: Time from trauma to initiation of renal replacement therapy in trauma patients with acute kidney injury grouped according to precense of rhabdomyolysis.

Further, the mortality rate in patients without rhabdomyolysis was lower at three months (17\% versus $50 \%, p=0.03$, respectively) and one year $(22 \%$ versus $54 \%, p=0.04$, respectively) compared to patients with rhabdomyolysis (Two-sided Pearson's chi-square test) (Figure 1).

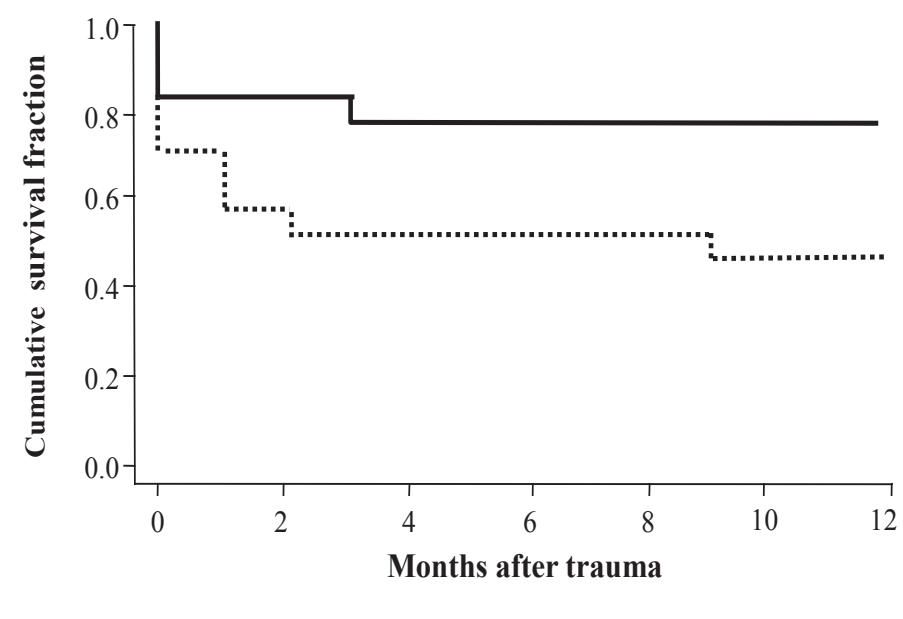

- Rhabdomyolysis

... Not rhabdomyolysis

Figure 2: Kaplan-Meier survival plot in trauma patients with acute kidney injury and renal replacement therapy grouped according to precense of rhabdomyolysis. 


\subsection{Paper II}

The paper included 36 adult trauma patients who developed AKI with need of CRRT lasting for more than 24 hours. Median age of the patients was 48 years, $86 \%$ were males and $43 \%$ had rhabdomyolysis. The mode of RRT was initially CVVHDF in all patients, but treatment was often switched to IHD after haemodynamic stabilization.

Data from the first five days of CRRT revealed that the median (interquartile range (IQR)) time per day with CRRT was 19 (15-21) hours, or $78 \%$ of the possible operative time. Serum concentrations of urea increased during CRRT with median $5 \%$ per day, whereas serum levels of creatinine deceased with median $5 \%$ per day. There was a significant correlation between daily CRRT duration and daily changes in serum urea and creatinine concentrations ( $\Delta$ urea, $\mathrm{r}=0.60, \mathrm{p}<0.01$ and $\Delta$ creatinine, $\mathrm{r}=0.43, \mathrm{p}=0.01$ ). CRRT interruptions were caused by filter clotting ( $54 \%$ ), therapeutic interventions $(25 \%)$, catheter related problems $(10 \%)$, filter time out (6\%) and diagnostic procedures $(6 \%)$. With the dialysis dose achieved in these patients, 19.1 and 14.1 hours per day of CRRT were required in order to maintain stable levels of urea and creatinine, respectively. In subgroup analysis comparing the reasons for CRRT interruption, those with rhabdomyolysis had more frequent therapeutic interventions ( $38 \%$ versus $12 \%, \mathrm{p}<0.01)$ and less frequent filter time-out

( $2 \%$ versus $10 \%, \mathrm{p}=0.04$ ) compared to patients without rhabdomyolysis, respectively. Patients with and without rhabdomyolysis had a similar correlation between median daily CRRT duration and median $\Delta$ urea $(\mathrm{p}=0.71)$ as well as median $\Delta$ creatinine $(\mathrm{p}=0.36)$. 
In additional unpublished analysis comparing patients with and without rhabdomyolysis, a difference in daily CRRT duration was present the first three days during treatment, but not from day four (Table 7).

Table 7: Daily duration of continuous renal replacement therapy

\begin{tabular}{llll}
\hline $\begin{array}{l}\text { Dialysis } \\
\text { (hours per day) }\end{array}$ & $\begin{array}{l}\text { Rhabdomyolysis } \\
(\mathbf{n}=\mathbf{1 7})\end{array}$ & $\begin{array}{l}\text { Not rhabdomyolysis } \\
(\mathbf{n}=\mathbf{2 2})\end{array}$ & $\begin{array}{l}\text { p- } \\
\text { value }\end{array}$ \\
\hline Day 0 $(\mathrm{n}=39 / 17 / 22)$ & $17.0(12.0-21.5)$ & $23.0(17.8-24.0)$ & 0.02 \\
Day 1 $(\mathrm{n}=35 / 15 / 20)$ & $18.0(13.0-21.0)$ & $23.0(20.0-24.0)$ & 0.01 \\
Day 2 $(\mathrm{n}=33 / 13 / 20)$ & $12.0(6.5-21.5)$ & $22.0(19.0-24.0)$ & 0.03 \\
Day 3 $(\mathrm{n}=31 / 12 / 19)$ & $14.0(7.5-21.0)$ & $22.0(16.0-24.0)$ & 0.05 \\
Day 4 $(\mathrm{n}=24 / 9 / 15)$ & $19.0(18.0-23.0)$ & $22.0(11.0-24.0)$ & 0.69 \\
\hline
\end{tabular}

Table 7: Daily duration of continuous renal replacement therapy (CRRT) in trauma patients with acute kidney injury (AKI) grouped according to precense of rhabdomyolysis. Data are presented as median (interquartlie range) and compared using two-tailed Mann-Whitney U test. N: Number.

In detailed analysis of blood sample results during the first five days of CRRT, we further explored the daily changes in urea-, creatinine-, bicarbonate-, base excess-, potassium- and CK concentrations (Figure 3).
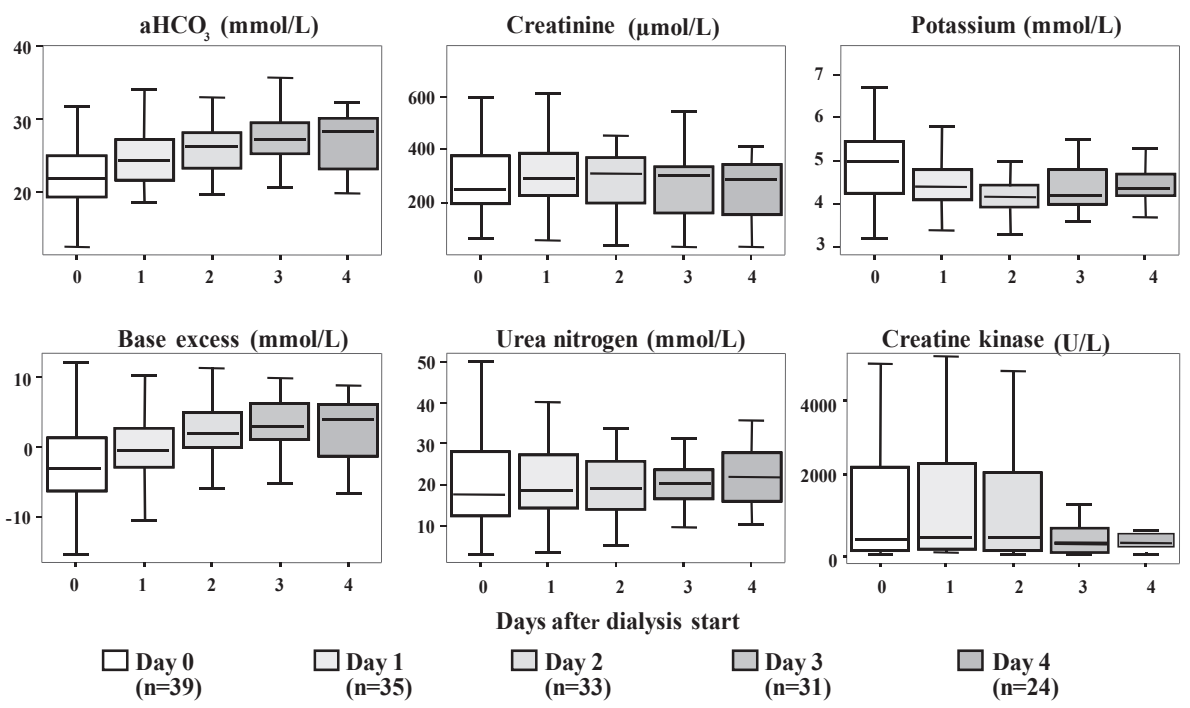

Figure 3: Blood sample analyses from the first five days after initiation of continuous renal replacement therapy in trauma patients with acute kidney injury treated. Data are presented as box plots with medians in $25^{\text {th }}$ and $75^{\text {th }}$ percentile boxes where outliers and extreme values are deleted. 


\subsection{Paper III}

The study included 245 adult resuscitated, comatose OHCA patients with mean age 61 years and $84 \%$ males. CA was witnessed in $87 \%$, bystander CPR was performed in $87 \%$, initial shockable rhythm was present in $67 \%$, and median time to ROSC was 25 minutes. All patients were treated according to our SOP including the use of TTM with target temperature set at $33{ }^{\circ} \mathrm{C}$ (degrees Celsius) for 24 hours.

Among the included patients, $4 \%$ had previously known CKD and $46 \%$ developed AKI. The 112 patients with AKI consisted of 58 (52\%) stage 1, 28 (25\%) stage 2 and $26(23 \%)$ stage 3, respectively. Overall six-month outcome revealed that $46 \%$ died and $50 \%$ had good neurological outcome. There was a significant difference in cumulative six-month survival in the compared kidney function groups ( $\mathrm{p}<0.01$ ), with favourable survival rates in patients without kidney disease. In univariate analyses, the presence of AKI was significantly associated with six-month mortality (OR 3.17, $95 \%$ CI 1.95-5.43, $\mathrm{p}<0.01)$ and good neurological outcome (OR 0.28, $95 \%$ CI 0.16-0.48, $<<0.01$ ). RRT was used in 18 patients with AKI, and indications for RRT were acidosis in $94 \%$, fluid overload in $72 \%$, hyperkalaemia in $50 \%$, rhabdomyolysis in $22 \%$ and uraemia in $11 \%$ of patients. AKI patients with and without RRT had comparable six-month mortality (50\% versus $61 \%$, respectively, $\mathrm{p}=0.40$ ) and good neurological outcome ( $44 \%$ versus $35 \%$, respectively, $\mathrm{p}=0.42$ ), even after excluding those patients where RRT was withheld due to futility. 
In additional unpublished subgroup analyses time from OHCA to initiation of RRT was similar in patients with and without rhabdomyolysis (median 1 day versus 1 day, $p=0.43$, respectively) (Two-tailed Mann-Whitney U test) (Figure 4).

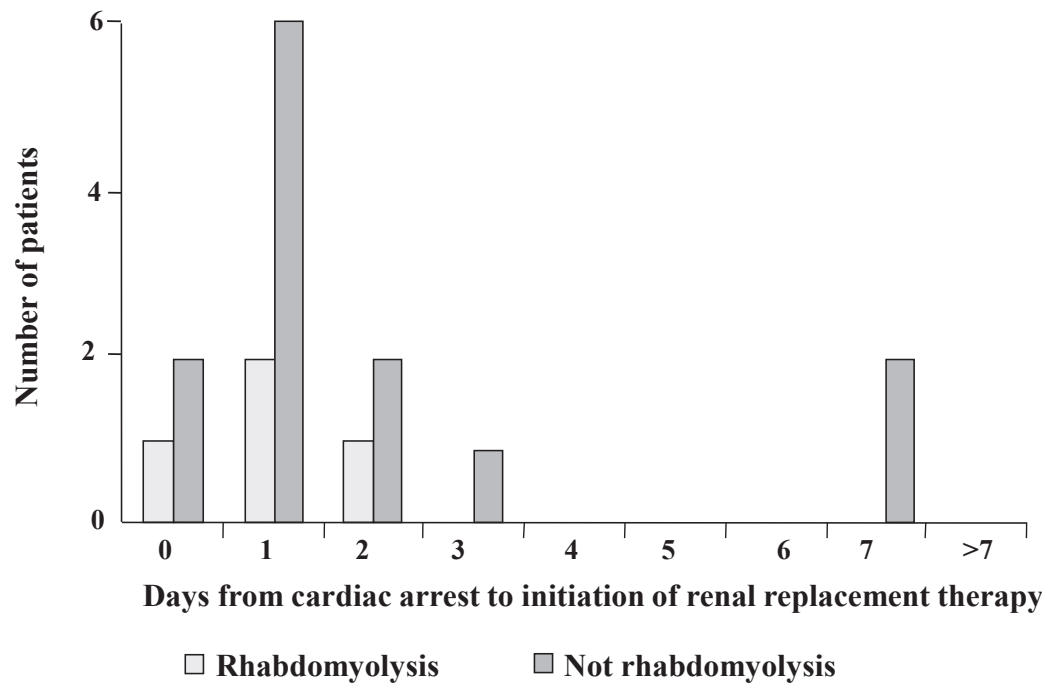

Figure 4: Time from cardiac arrest to initiation of renal replacement therapy in out-of-hospital cardiac arrest patients with acute kidney injury grouped according to precense of rhabdomyolysis.

Further, there were no statistical significant differences in outcomes when comparing patients with AKI KDIGO stage 3 with and without RRT (Table 8).

Table 8: Outcome in patients with and without renal replacement therapy

\begin{tabular}{llll}
\hline Assessed outcomes & $\begin{array}{l}\text { AKI stage 3 with } \\
\text { RRT (n=18) }\end{array}$ & $\begin{array}{l}\text { AKI stage 3 without } \\
\text { RRT (n=8) }\end{array}$ & $\begin{array}{l}\text { p- } \\
\text { value }\end{array}$ \\
\hline CPC 1-2 at 6 months & $6(33)$ & $1(13)$ & 0.352 \\
Dead at 6 months & $9(50)$ & $7(88)$ & 0.189 \\
\hline
\end{tabular}

Table 8: Outcome in out-of-hospital cardiac arrest patients with acute kidney injury stage 3 comparing patients with and without renal replacement therapy. Data are expressed as number (percent) and compared using two-sided Fisher exact test. AKI: Acute kidney injury, RRT: Renal replacement therapy, CPC: Cerebral performance category, n: Number. 


\subsection{Paper IV}

This paper included adult resuscitated, comatose OHCA patients with spot urine samples collected for AKI biomarker analyses. Among the 195 patients, $85 \%$ were males and mean age was 60 years. The OHCA was witnessed in $85 \%, 66 \%$ had initial shockable rhythm and median time to ROSC was 25 minutes. AKI occurred in $45 \%$ of the patients, with $27 \%$, $12 \%$ and $7 \%$ with KDIGO stage 1, 2 and 3, respectively. Overall six-month outcome revealed that $45 \%$ died and $51 \%$ had good neurological outcome. In all additional analyses, calculations were performed on PNO.

In univariate analysis, cystatin $\mathrm{C}$ and NGAL concentrations at admission and day three were independent risk factors for AKI, mortality and PNO, whereas [TIMP2]·[IGFBP7] levels was only a risk factor for AKI at admission. The highest OR (95\% CI) was for AKI NGAL at day three with OR 5.65 (2.81-11.3), for mortality NGAL at admission with OR 4.51 (2.46-8.28) and for PNO NGAL at day three with OR 4.21 (2.18-8.12). In multivariate analysis combining clinical parameters and biomarkers, the AuROCs (95\% CI) were $0.774(0.700-0.848), 0.812(0.751-0.873)$ and $0.819(0.759-0.878)$ for AKI, mortality and PNO, respectively. The discriminating power was not uniformly improved in models combining biomarkers and clinical parameters when compared to the use of biomarkers alone. In subgroup analysis exploring the biomarkers ability to predict severe AKI (KDIGO stage 2 and 3) compared to mild AKI (KDIGO stage 1), cystatin C and NGAL at day three were statistically significant better in predicting severe than mild AKI. 
In additional unpublished results we present the AuROC curves for the AKI biomarkers'

ability to predict AKI, neurological outcome and mortality alone, and in the best models

combining biomarkers and clinical parameters (Figure 5).

\section{Prediction of AKI ( $n=164)$}

Biomarkers alone

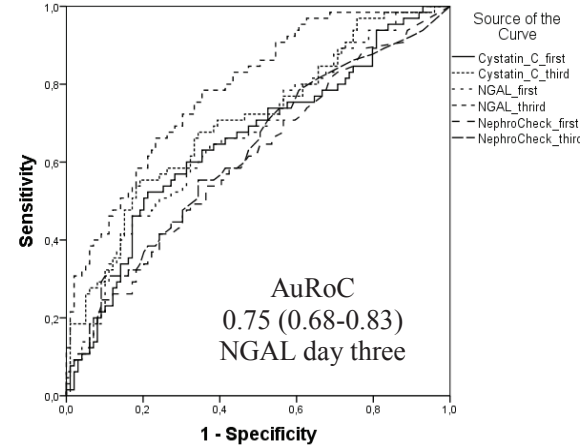

Prediction of mortality $(n=164)$

Biomarkers alone

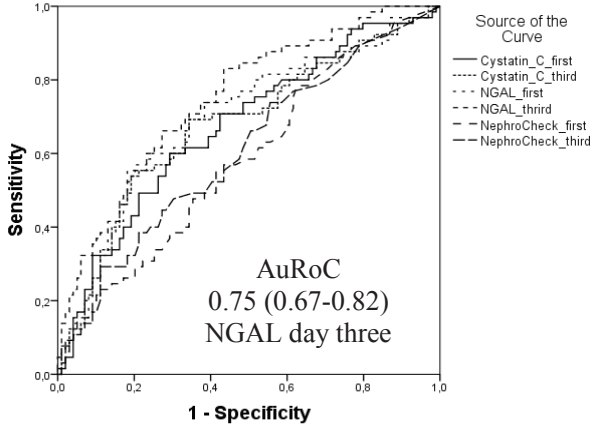

Predictors of poor neurological outcome $(n=164)$ Biomarkers alone

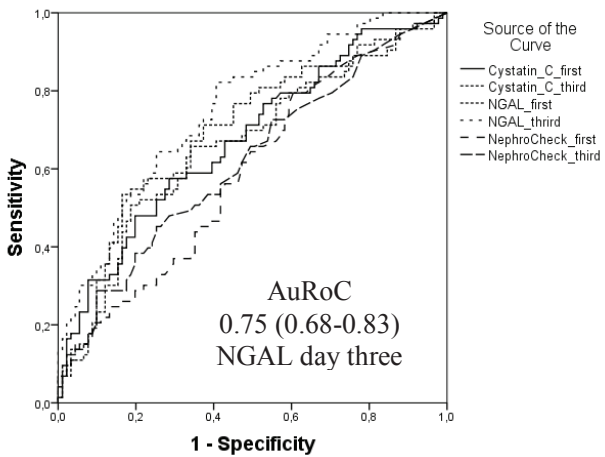

Best model with biomarker and clinical parameters

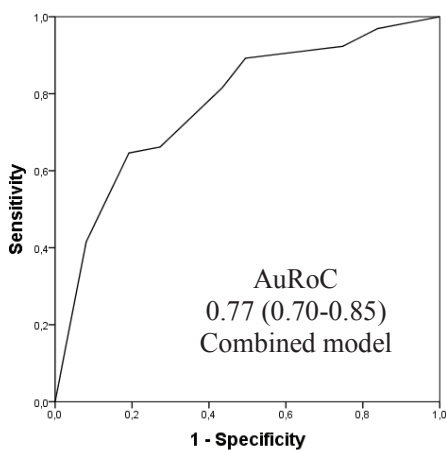

Parameters in model

SOFA score day 0

Serum urea day 0

Urine NGAL day 3

Best model with biomarker and clinical parameters

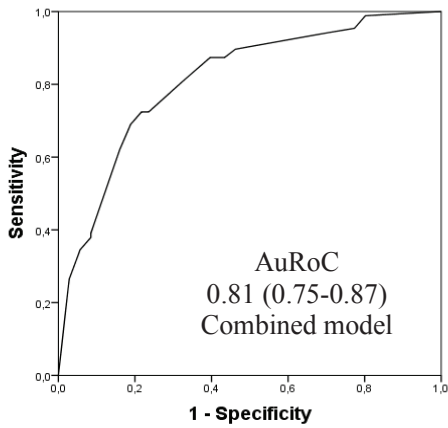

Parameters in model Lack of initial VT/VF

Presence of AKI

SOFA score day 0

Urine NGAL at admission

Best model with biomarker and clinical parameters

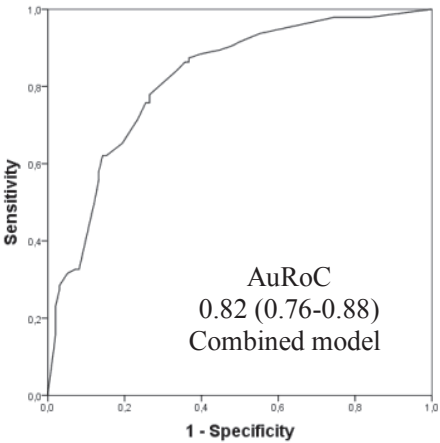

Parameters in model Lack of Initial VT/VF

Presence of AKI

Whole blood base excess day 0 SOFA score day 0

Urine Cystatin $\mathrm{C}$ at admission

Figure 5: Area under the receiver operating characteristics plots for the predictive models for acute kidney injury mortality and poor neurological outcome in cardiac arrest patients. Data are presented as area under the curve (AuRoC) with $95 \%$ confidence interval for the best models. SOFA: Sequential organ failure assessment, NGAL: Neutrophil gelatinase associated lipocalin, VT/VF: Ventricular tachycardia/ ventricular fibrillation, AKI: Acute kidney injury. 


\section{Discussion}

\subsection{Paper I}

Comparing epidemiological data on post-traumatic AKI in previous and present studies is challenging due to many different definitions of trauma and AKI. The reported occurrence of AKI after trauma has ranged from $0.1 \%$ to $31 \%[10,177,178]$. In more recent studies of severely injured trauma patients applying modern AKI criteria, the incidence of posttraumatic AKI is reported to be $15-48 \%[51,53-56]$, and RRT is described to be used in 6-15\% of trauma patients admitted to the ICU $[53,54]$.

We found that the occurrence of post-traumatic AKI with RRT was $0.5 \%$ of all hospitalized trauma patients, whereof many suffered only minor trauma with low ISS [179]. In agreement with previous findings, we found that $8.3 \%$ of major trauma patients admitted to ICU had AKI necessitating RRT $[53,54]$. Additionally, we calculated a population based incidence of post-traumatic AKI with need of RRT being 1.8 persons per million inhabitants per year.

The risk of developing post-traumatic AKI was in our study several times higher in males compared to females, which has been observed in many other studies $[55,56,177,180]$, although one study showed the opposite [8]. The gender difference in our study persisted even after adjustment for the actual number of males and females, suggesting that men may be more prone to develop post-traumatic AKI than women. We did, however, not adjust for the severity of trauma, and the observed gender difference might be due to more severe injuries in males compared to females. Nevertheless, in one study on risk factors for post-traumatic AKI, diabetes mellitus, male sex and severe injury were strongly associated with AKI development [8].

An interesting finding in our study was the frequent use of nephrotoxic agents compared to previous reports of post-traumatic AKI $[10,177]$. Iodinated radiocontrast agents 
were administrated to $29 \%$ of the patients during computer topography, $5 \%$ during angiography and additionally $38 \%$ during combined computer topography and angiography [179]. Radiocontrast agents were often used during diagnostic and/or therapeutic interventions of spleen-, liver- and/or pelvic bleedings [181-183]. The limited clinical data on contrast agents as a risk factor for AKI in trauma patients are showing conflicting results $[54,56,184,185]$, and it seems like these agents are currently being used in most major trauma patients [56]. In studies comparing low and high exposure of iodinated radiocontrast agents, the use of high exposure has not been associated with increased risk of post-traumatic AKI $[8,184,186]$.

We observed a relatively high incidence of urinary tract obstruction (12\%) as a possible contributing cause of AKI, including $2 \%$ with obstruction of the urinary catheter, and $10 \%$ with obstruction of both ureters. As all major trauma patients had urinary catheters inserted, one should expect that urinary tract obstruction was a rare risk factor for AKI in this patient group. Post-renal AKI has previously been reported to occur in $2.5 \%$ of trauma patients and in $10 \%$ of general ICU patients suffering from AKI $[177,187,188]$. Urinary tract obstruction in trauma victims might be due to traumatic injuries such as retroperitoneal haematoma blocking the ureter, or as part of an intrapelvic compartment syndrome $[189,190]$. Additionally, some of the patients in our study underwent pelvic- or abdominal packing as part of damage control surgery [191], and how this might cause post-renal AKI in trauma patients deserves more research.

After publication of our study, there has been focus on the potential adverse effects of fluids containing hydroxyethyl starch in different patient cohorts. While these products have been associated with development of AKI and adverse outcome in septic patients [192, 193], it has not been certainly confirmed in surgical patients [194]. Although we lack data in our patient cohort, we know that fluids containing hydroxyethyl starch was commonly 
used at our hospital during the study period. The use of such fluids in trauma patients was associated with decreased incidence of AKI in one study [195], while several other studies have shown the opposite $[56,196]$.

AKI is a strong predictor of mortality in trauma patients [51, 54-56, 61], and fatality rates in post-traumatic AKI with need of RRT has been described to be around $50 \%$ [177]. In comparison, the mortality in our small patient group was $40 \%$ after one year, and the good outcome might be due to young age and good health status prior to the trauma. Our observation that increased age was a risk factor for death was not surprising, as this has previously been shown in general ICU patients $[44,197]$ and trauma patients with AKI [56]. Unfortunately, we are unable to perform a long-time follow-up of our study population in order to explore the extent of complications such as chronic pain, reduced quality of life, physical disability and/or post-traumatic stress disorder.

Renal recovery in unselected ICU populations has been reported to occur in 78-95\% of the patients, and is obviously dependent on the definition of renal recovery and the time period considered $[5,16,198]$. As in two other studies of post-traumatic AKI, we found that no patient required chronic RRT $[10,56]$. Considering long-time effects of AKI on the development of CKD, one year observational time is relatively short, and it would be interesting to follow the patients' kidney function over a longer time period. The overall good renal recovery rate observed in our study population was probably because our patients were relatively young, and that those with known CKD were excluded from the study.

\subsection{Paper II}

Our study revealed that the trauma patients received CRRT median 19 hours per day, i.e. $78 \%$ of the total possible time [201], still comparable to the 19-23 hours per day in previous studies of general ICU patients with AKI undergoing RRT [35, 199, 200]. Probable reasons 
for the relatively short daily CRRT duration in our patients might have been bleeding limiting anticoagulation, absence from the ICU due to diagnostic procedures and/or therapeutic interventions, and/or technical difficulties in maintaining dialysis circuit patency.

We observed that the daily CRRT duration to maintain serum concentrations were above 19 hours per day for urea, and only around 14 hours per day for creatinine. A clear limitation to these data, however, is that we were unable to present exact data on the delivered CRRT dose in the studied population. In contrast, 16 hours of CRRT per day was needed to maintain serum concentrations of both urea and creatinine in a previous study of mixed ICU patients [35]. The observed difference in daily RRT duration for maintaining urea and creatinine concentrations between trauma patients and general ICU patients could be explained by extensive muscular damage [202, 203], which may cause increased production of protein degradation products such as urea.

Filter clotting was the main reason for interruptions of CRRT in previous studies of mixed ICU patients, accounting for $74-78 \%$ of the temporary discontinuations $[35,200]$. The reasons for temporary interruptions during CRRT in our study was filter clotting (54 \%), therapeutic interventions (25\%), catheter related problems (10\%), filter time out (6\%), and diagnostic procedures $(6 \%)$. Our study certainly revealed that there is a potential for improvement, since most of the CRRT interruptions were due to technical difficulties such as filter clotting or catheter-related problems.

There was no difference in the time interval from trauma to initiation of RRT in our patients with or without rhabdomyolysis. However, those with rhabdomyolysis had a better survival rate, and we might speculate that the observed difference in mortality was because they were younger with less chronic co-morbidity compared to patients without rhabdomyolysis. Additionally, those with rhabdomyolysis had shorter daily duration of CRRT the first three days after initiation of RRT. A plausible reason might be that they often 
suffered from severe bleeding and underwent diagnostic and/or therapeutic interventions remote form the ICU. Another interesting finding in the blood sample analyses of total patient cohort was that some of the patients developed a metabolic alkalosis a few days after

initiation of CRRT (Figure 3). Although we do not know the reason for this, it might be due to the RRT and/or the use of forced alkaline diuresis frequently applied in these patients prior to initiation of RRT.

Although clinical data on RRT quality are available in general ICU patients, data are lacking in the ICU subgroup of trauma patients. Trauma patients might differ from other ICU patients in several aspects of CRRT; first, the muscular damage might lead to a rise in metabolic waste product such as urea that should be eliminated from the body through the kidneys. Second, trauma patients are initially threatened by severe bleeding limiting the use of anticoagulation during CRRT. Third, frequent diagnostic procedures and therapeutic interventions remote from the ICU limit the time available for CRRT. In summary, we might speculate that trauma patients should receive increased dialysis doses during CRRT compared to other ICU patients, especially in the initial phase. However, there are no such specific treatment recommendations adjusted for trauma patients.

\subsection{Paper III}

In a recent systematic review and meta-analysis, overall incidence of AKI after CA was $37 \%$ [85], and among the included studies ranging from $12 \%$ to $81 \%$ [80-85]. In comparison, we found that $46 \%$ of the OHCA victims developed AKI within three days [204]. Reported occurrences of AKI may wary due to several factors including study population, as OHCA and in-hospital CA are different subgroups of CA victims [205]. In a study of mixed CA patients, in-hospital CA was found to be an independent predictor of AKI development [84], possibly because of pre-existing disease leading to hospital admission and/or other causes of 
the CA. AKI occurrence also depends on the AKI definition used, and time period considered. Moreover, several factors such as pre-morbid status, pre-hospital factors, extent of reperfusion injuries and post-resuscitation care will affect the development of AKI. Finally, it is reasonable to assume that the quality of care may influence the extent of organ failures, but such parameters are difficult to measure in clinical studies [206]. CKD was present in $4 \%$ of the patients in our study, comparable to previous CA studies [81, 84]. However, CKD was present in $10 \%$ of a large population-based Norwegian cohort with similar age [207], and it is likely that the true prevalence of CKD in our study population was underestimated, because we based our CKD diagnosis on the medical history [204].

In our study we found that chronic hypertension, malignant disease, unwitnessed CA, long time to ROSC and high SAPS II- and SOFA scores were risk factors for AKI [204]. Preexisting CKD and hypertension are known risk factors for AKI in general ICU patients, and high severity of illness scores are considered to be markers of multiple organ failure often present in patients with severe AKI [208]. In CA patients, unwitnessed CA, non-shockable rhythm and long time to ROSC are factors associated with unfavourable outcome $[85,124,209]$. A remarkable finding in our study was that rhabdomyolysis, a previously undescribed risk factor for severe AKI after OHCA, was present in $2 \%$ of the patients without kidney disease, $10 \%$ of the AKI patients, and $28 \%$ of the AKI patients undergoing RRT. Additionally, our unpublished sub-group analysis revealed that CA patients with and without rhabdomyolysis had similar time from CA to initiation of RRT, although a low number of patients was studied. A recent systematic review and meta-analysis revealed that the serum CK level predicted rhabdomyolysis-induced AKI, even if the correlation between serum CK level and AKI occurrence was stronger in cases of traumatic rhabdomyolysis compared to other causes of rhabdomyolysis [144]. 
AKI after CA was associated with increased mortality in a recent systematic review and meta-analysis, but the effect on neurological outcome was unsure since the observed increased risk was not confirmed after corrections for confounders [85]. In our study, published after this review, we found that six-month mortality and neurological outcome were favourable in patients without kidney disease compared to those experiencing AKI, also in data adjusted for confounding factors [204]. The outcome findings regarding mortality and neurological outcome are often similar, since dead people are rated with a CPC of $5[87,88]$. In order to improve outcome after CA, optimizing and standardizing our current approach to CA resuscitation and post-resuscitation care is essential [210], and future studies are needed to evaluate different treatment alternatives.

The reported use of RRT in CA patients with AKI has been 4-33 \% [81, 84-86]. We found that $16 \%$ of our OHCA patients with AKI underwent RRT, and that RRT was withheld due to futility in $9 \%$ of the AKI patients. Interestingly, six-month mortality and neurological outcome were similar in AKI patients with and without RRT, even after excluding those where RRT was withheld due to futility. This finding was confirmed in our unpublished sub-group analysis revealing a similar prognosis in CA patients with AKI stage 3 with and without RRT, although the number of patients was low. In previous CA studies, AKI with use of RRT was identified as an independent predictor of bad outcome in a large registry study [211], but was not associated with unfavourable outcomes in three recent studies $[81,84,86]$. Many studies have therefore reported a relative good outcome in CA patients undergoing RRT, and there might be several reasons for this observation. A plausible explanation might be that clinicians perform well in selecting patients with anticipated good prognosis for RRT. An alternative hypothesis is that the use of RRT may have beneficial effects in this patient group, possibly by removing circulating harmful substances from the body. Post-cardiac arrest patients are sepsis-like with early excessive cytokine release [212], 
and the use of RRT has been associated with beneficial effects in septic patients [213, 214].

Moreover, the use of RRT has in rhabdomyolysis shown to increase the clearance of muscular degradation products [138], improve mitochondrial function and inhibit cell apoptosis [215]. One clinical study revealed that the use of high-volume haemofiltration in OHCA patients was associated with improved survival [216], but more studies are indeed warranted.

\subsection{Paper IV}

The currently available biomarkers aimed to predict AKI have many shortcomings limiting their clinical use $[38,217,218]$. In general ICU patients, cystatin C, NGAL and [TIMP-2]·[IGFBP7] measured in blood and/or urine are among the best predictors of subsequent AKI [142, 219-221]. In CA patients there are some data revealing that NGAL measured in blood within four hours after ROSC is a predictor of AKI [209]. In agreement with this, we found that cystatin C, NGAL and [TIMP-2]·[IGFBP7] concentrations measured in spot urine of OHCA patients at admission were predictors of AKI. At day three cystatin C, NGAL, but not [TIMP-2]·[IGFBP7], was able to predict subsequent AKI, possibly due to the relatively short half-life of the latter markers. In a subgroup analysis, we additionally observed that urine cystatin C and NGAL levels at day three performed better in predicting moderate to severe AKI (KDIGO stage 2 and 3) compared with mild AKI (KDIGO stage 1). This is interesting, since worsened AKI severity is associated with increased need of RRT and reduced survival [222].

The biomarkers cystatin C, NGAL and [TIMP-2]·[IGFBP7] have in general ICU patients been prognostic predictors of mortality [223-225]. In two recent CA studies, NGAL levels measured in blood samples were able to predict mortality [124, 209], and in one of the studies NGAL concentrations also predicted neurological outcome [209]. Likewise, we found that the urine levels of cystatin C and NGAL, but not [TIMP-2]·[IGFBP7], were statistically 
associated with mortality and PNO. We might speculate that cystatin C and NGAL are markers of whole body ischemia and reperfusion injuries, whereas TIMP-2 and IGFBP7 probably are more kidney-specific markers.

Predictive models of outcome after CA are warranted since futile treatment is a huge problem in medical practice. Patients may have late awakening after OHCA, and clinicians must be cautious in not prematurely terminate life in patients with the potential for full neurological recovery [226]. In fact, two studies of CA patients have revealed that more than half of the deaths among initial survivors were associated with withdrawal of active ICU treatment $[75,227]$. Many efforts have therefore been suggested in order to improve prognostication after CA, but we still lack a reliable tool for the early prediction of poor outcome in these patients [228].The addition of biomarkers to clinical parameters have been suggested in order to improve outcome prediction after CA [229-231], but as in our study the discriminating power between favourable and unfavourable outcome is limited. However, in one study, a multimodal scorings system consisting of seven patient parameters at an early stage after ICU admission had a good ability to predict neurological outcome at ICU discharge [231]. Due to the restrictions of such predictive models, they are not ready for use in clinical practice to decide treatment allocation of patients. Recent European guidelines for post-resuscitation care therefore recommend a multimodal strategy with prolonged observation in cases with uncertain outcome [73]. We hope that the main results from the NORCAST study will contribute to improved prognostication after CA, especially since the clinicians were blinded for prognostic markers in order to avoid self-fulfilling prophecies in the study. 


\subsection{Methodological considerations}

In assessing internal validity, the key concept is whether observed changes can be attributed to the exposure and not to other possible causes. Internal validity is therefore a question of study quality in observational studies, and whether the compared groups really are comparable. The most important domains to be considered in cohort design are presented in Table 9 where the papers in this thesis are assessed to be of high, unclear or low quality judged by the author of this thesis.

Table 9: Assessment of the quality of studies included in this thesis

\begin{tabular}{|c|c|c|c|c|}
\hline Domains considered & Paper I & Paper II & Paper III & Paper IV \\
\hline $\begin{array}{l}\text { Selection bias } \\
\text { Are compared patients } \\
\text { from the same cohort and } \\
\text { time period? }\end{array}$ & High & High & High & High \\
\hline $\begin{array}{l}\text { Selection bias } \\
\text { Are there any losses to } \\
\text { follow-up? How are } \\
\text { these accounted for? }\end{array}$ & High & High & High & High \\
\hline $\begin{array}{l}\text { Information bias } \\
\text { Are the methods used to } \\
\text { collect data adequate or } \\
\text { not? }\end{array}$ & Unclear & Unclear & High & High \\
\hline $\begin{array}{l}\text { Information bias } \\
\text { Are exposures and } \\
\text { outcomes measured } \\
\text { objectively? }\end{array}$ & Unclear & Unclear & High & High \\
\hline $\begin{array}{l}\text { Confounding factors } \\
\text { Are confounding factors } \\
\text { adequately controlled } \\
\text { for? }\end{array}$ & Low & Low & Unclear & Unclear \\
\hline $\begin{array}{l}\text { Statistical power } \\
\text { Do the studies have } \\
\text { adequate statistical } \\
\text { power? }\end{array}$ & Low & Low & Unclear & Unclear \\
\hline $\begin{array}{l}\text { Other bias } \\
\text { Are there other factors } \\
\text { present that could limit the } \\
\text { quality assessment? }\end{array}$ & Low & Low & Low & Low \\
\hline
\end{tabular}


In the trauma studies (Paper I and II), it is unclear to which extent the retrospective design may have influenced the quality of data collection. Not all outcome variables were objectively measured, as for instance the reasons for temporary interruptions during CRRT that to some degree was dependent on the author's judgement. Moreover, no confounding factors for the association between AKI with need of RRT and mortality were considered or controlled for, although some were likely to be present. Finally, the number of patients included was only 42 and 36, resulting in a limited statistical power and a probability for false negative effect (type II error).

In the OHCA studies (Paper III and IV), there might be confounding factors for the association between exposure (AKI) and outcome (mortality and neurological outcome) not adequately controlled for. As an example, we were unable to assess the confounding effect of RRT because no patients without AKI received RRT. Additionally, the possible confounding effect of withholding and/or withdrawing treatment was neither assessed. Furthermore, although there were 245 and 195 patients included in these studies, an a priori sample size calculation would be preferable. Finally, a general limitation to the quality assessment of all papers presented is, off course, the authors ability to evaluate own work marked as "other bias" in Table 9.

External validity is considered as the transferability of results, meaning whether the results can be applied in other settings. The key question in assessing external validity is the degree to which the conclusions in a study would hold for other persons in other places and at other times. There are several limitations to the generalizability of our results, as the studied populations (trauma and OHCA patients) are quite differently handled around the world, depending on recourse availability and established medical practice. Additionally, prehospital handling, in-hospital care and rehabilitation of these patient groups may vary across sites limiting the external validity of our findings. 
All studies included in this thesis (Paper I-IV) have additional limitations to the design of cohort studies that should be taken into account in the interpretation of the results. Since the included patients are not randomized, there might be systematic differences between compared groups. Furthermore, the association observed between risk factors and outcomes does not necessarily mean that there is a causal relationship. In the trauma studies (Paper I and II), it would be preferable to include all severities of AKI, and to have a control group of trauma patients without AKI. Moreover, the quality of the studies would be improved if we could present exact data on the prescribed and delivered CRRT doses. Finally, it would probably also be appropriate to replace the Pearson's chi-square test with the Fisher's exact test in the analysis of some of the data with very few observations in each group. In the OHCA studies (Paper III and IV), a longer time period than six months follow-up would have been preferable. The occurrence of kidney disease was probably underestimated since CKD was diagnosed based on the medical history, and AKI criteria were applied for only three days with missing bodyweight information in some of the patients. In Paper IV, there were several limitations to the measurement of biomarkers as the time from CA to urine sampling varied both at admission and at day three. The urine samples collected at admission could potentially be diluted with urine present in the urinary bladder prior to the arrest. Moreover, the urine samples were not handled exactly as recommended, but we still consider the results to be valid based on results from previous studies and our pilot study [174-176].

The papers included in this thesis also have some methodological strengths. Cohort design is suitable for calculating incidence rates and examinations of multiple effects of a single exposure. Cohort studies are also appropriate for development of new hypothesis that could be tested out in subsequent trials [232]. In all studies (Paper I-IV), the included patients came from the same cohort and time period, using defined inclusion and exclusion criteria and with no loss to follow-up. In the trauma studies (Paper I and II), several registries were 
crosschecked during the inclusion of patients, making it unlikely that patients were missed. Additionally, a uniform registration process was secured as only one investigator collected the data, intending to use clear and commonly applied definitions of variables. In the epidemiological study (Paper I), the setting with a single regional trauma referral centre made it possible to present population based incidence data, and the Norwegian Renal Registry made it possible to present reliable data on renal outcome.

In the OHCA studies (Paper III and IV), there were many included patients enhancing the statistical power of the study. Additionally, there was a prospective study design and a priori planned collection of data. Commonly applied definitions of variables were used, and kidney disease was classified using up-to date CKD and AKI definitions. Patients were treated according to our SOP documenting good and stable outcome over time $[74,75,204]$. Generally, we aimed to follow international recommendations for reporting of data from OHCA patients and observational studies [88, 233]. Finally, the AKI biomarkers were tested using some of the most promising biomarkers available in a population with a high pre-test probability of the considered outcomes (Paper IV). 


\subsection{Implications for clinical practice and future research}

Paper I revealed that nephrotoxic agents and urinary tract obstruction might be important risk factors for AKI in trauma patients. These findings indicate that trauma patients undergoing angiographic embolization and/or damage control surgery should be closely followed afterwards in respect to their kidney function, and that alternative treatment options should be considered in high-risk patients. The importance of these findings should be evaluated in future studies considering both effects and side effects, and maybe compare it with other treatment alternatives of acute bleeding. Indeed, it would be feasible to facilitate trials comparing different interventions.

Paper II showed that trauma patients received inadequate RRT doses in order to achieve uraemic control, and technical difficulties were frequent causes of temporary interruptions. Since 2006 we have implemented educational programs for RRT run by dedicated ICU nurses. Our department has developed a CRRT protocol with standardized indications for CRRT, weight adjusted dialysis doses, and criteria for discontinuation of CRRT. Finally, we have changed anticoagulation during CRRT from systemic heparin to regional citrate. More studies on RRT quality in this patient group is certainly needed, and future studies of increased RRT dose, timing of initiation of RRT and/or improvement of technical skills would be preferable and very interesting.

Paper III showed that OHCA patients developing AKI with and without RRT had a similar prognosis, although those with RRT were more severely ill. Noteworthy, the clinicians have to consider these findings when deciding which patients should be offered RTT or not. Handling of AKI in CA patients and the use of RRT was not even mentioned in the most recent European or American guidelines for post-resuscitation care [73, 234]. We need to perform more clinical studies evaluating the effects of RRT after CA, and also evaluate consequences and treatment of rhabdomyolysis as a risk factor for AKI after CA. 
Paper IV revealed that urine cystatin C and NGAL at admission and day three were independent risk factors for $\mathrm{AKI}$, mortality and $\mathrm{PNO}$ in resuscitated, comatose $\mathrm{OHCA}$ patients. Unfortunately, these findings have limited value in clinical decision making since the biomarker levels overlapped in the compared groups. However, these biomarkers might be useful in clinical research in risk stratification of patients, as subjects with moderate biomarker levels probably have the most modifiable disease process and are suitable for inclusion in randomized clinical trials. In future studies, it would be possible to improve the performance of biomarkers with proper selection of patients, optimal sample collection and/or combined with other parameters.

There is an increasing incidence of AKI and use of RRT that is expected to rise even further $[67,94,235,236]$, in a recently published multicentre study $57 \%$ of ICU patients experienced AKI, and $13.5 \%$ were treated with RRT [222]. We therefore need more highquality research on AKI further exploring risk factors, pathophysiology, prophylaxis, diagnosis, treatment, prognosis and follow-up. Future studies should include a wide variety of study designs (including experimental laboratory research, observational studies, interventional trials and systematic reviews), and the available research results should be graded for quality or certainty of evidence, and result in practical treatment recommendations available for bed-side health personnel. Considering the substantial complexity of the disease process, there seems to be no emerging miracle cure available. However, there are some promising alternatives for future improvements out of the scope of this thesis, including new functional tests of kidney function, remote ischemic preconditioning, haemodynamic optimization, immune-modulating RRT filters, drug dosing during AKI and/or RRT, timing of RRT initiation, and the use of recombinant embryonic stem cells. Future studies should also explore long-time outcomes after an episode of AKI, including factors influencing renal recovery and the effects of ambulatory follow-up. 


\section{Conclusions}

The conclusions regarding the specific research questions are:

1. AKI necessitating RRT following traditional criteria was rare among trauma patients, and the risk of this complication was higher in males compared to females. The mortality of post-traumatic AKI with RRT was modest, and renal recovery was excellent among survivors as none was dependent on RRT one year after trauma.

2. Trauma patients with AKI and RRT had relatively short median CRRT duration, and there was an association between daily CRRT duration and uraemic control defined as daily changes in blood creatinine- and urea concentrations. The patients achieved inadequate RRT dose in order to achieve uraemic control, and a relatively large proportion of the temporary CRRT interruptions were due to technical difficulties.

3. Kidney disease occurred in about half of patients successfully resuscitated from OHCA, and was associated with unfavourable six-month mortality and neurological outcome. AKI patients with and without RRT had comparable mortality and neurological outcome, even after excluding patients where RRT was withheld due to futility.

4. Urine cystatin $\mathrm{C}$ and NGAL concentrations at admission and day three were independent risk factors for AKI, mortality and poor neurological outcome in resuscitated comatose OHCA patients, whereas [TIMP-2]·[IGFBP7] levels only predicted AKI at admission. The discriminating power was not uniformly improved in models combining biomarkers and clinical parameters compared to the use of biomarkers alone. 


\section{References}

1. Thongprayoon C, Cheungpasitporn W, Srivali N, Ungprasert P, Kittanamongkolchai W, Kashani K (2016) The impact of fluid balance on diagnosis, staging and prediction of mortality in critically ill patients with acute kidney injury. Journal of nephrology 29:221-227.

2. Zhang L, Chen Z, Diao Y, Yang Y, Fu P (2015) Associations of fluid overload with mortality and kidney recovery in patients with acute kidney injury: A systematic review and meta-analysis. J Crit Care 30:860.e7-13.

3. Patschan D, Muller GA (2015) Acute kidney injury. Journal of injury \& violence research 7:19-26.

4. Bellomo R, Bagshaw S, Langenberg C, Ronco C (2007) Pre-renal azotemia: a flawed paradigm in critically ill septic patients? Contrib Nephrol 156:1-9.

5. Uchino S, Kellum JA, Bellomo R, Doig GS, Morimatsu H, Morgera S, Schetz M, Tan I, Bouman C, Macedo E, Gibney N, Tolwani A, Ronco C (2005) Acute renal failure in critically ill patients: a multinational, multicenter study. JAMA 294:813-818.

6. Hoste EA, Schurgers M (2008) Epidemiology of acute kidney injury: how big is the problem? Crit Care Med 36:S146-151.

7. Hilton R (2006) Acute renal failure. BMJ 333:786-790.

8. Bagshaw SM, George C, Gibney RT, Bellomo R (2008) A multi-center evaluation of early acute kidney injury in critically ill trauma patients. Ren Fail 30:581-589.

9. de Mendonca A, Vincent JL, Suter PM, Moreno R, Dearden NM, Antonelli M, Takala J, Sprung C, Cantraine F (2000) Acute renal failure in the ICU: risk factors and outcome evaluated by the SOFA score. Intensive Care Med 26:915-921.

10. Vivino G, Antonelli M, Moro ML, Cottini F, Conti G, Bufi M, Cannata F, Gasparetto A (1998) Risk factors for acute renal failure in trauma patients. Intensive Care Med 24:808-814.

11. Hoste EA, Dhondt A (2012) Clinical review: use of renal replacement therapies in special groups of ICU patients. Crit Care 16:201.

12. Druml W (2014) Systemic consequences of acute kidney injury. Curr Opin Crit Care 20:613-619.

13. Koyner JL, Cerda J, Goldstein SL, Jaber BL, Liu KD, Shea JA, Faubel S (2014) The daily burden of acute kidney injury: a survey of U.S. nephrologists on World Kidney Day. Am J Kidney Dis 64:394-401.

14. Giordana F, D'Ascenzo F, Nijhoff F, Moretti C, D'Amico M, Biondi Zoccai G, Sinning JM, Nickenig G, Van Mieghem NM, Chieffo A, Dumonteil N, Tchetche D, Barbash IM, Waksman R, D'Onofrio A, Lefevre T, Pilgrim T, Amabile N, Codner P, Kornowski R, Yong ZY, Baan J, Colombo A, Latib A, Salizzoni S, Omede P, Conrotto F, La Torre M, Marra S, Rinaldi M, Gaita F (2014) Meta-analysis of predictors of all-cause mortality after transcatheter aortic valve implantation. Am J Cardiol 114:1447-1455.

15. Rewa O, Bagshaw SM (2014) Acute kidney injury-epidemiology, outcomes and economics. Nature reviews Nephrology 10:193-207.

16. Bell M, Liljestam E, Granath F, Fryckstedt J, Ekbom A, Martling CR (2005) Optimal follow-up time after continuous renal replacement therapy in actual renal failure patients stratified with the RIFLE criteria. Nephrol Dial Transplant 20:354-360.

17. Bell M, Granath F, Schon S, Ekbom A, Martling CR (2007) Continuous renal replacement therapy is associated with less chronic renal failure than intermittent haemodialysis after acute renal failure. Intensive Care Med 33:773-780. 
18. Rimes-Stigare C, Awad A, Martensson J, Martling CR, Bell M (2012) Long-term outcome after acute renal replacement therapy: a narrative review. Acta Anaesthesiol Scand 56:138-146.

19. Rimes-Stigare C, Frumento P, Bottai M, Martensson J, Martling CR, Walther SM, Karlstrom G, Bell M (2015) Evolution of chronic renal impairment and long-term mortality after de novo acute kidney injury in the critically ill; a Swedish multi-centre cohort study. Crit Care 19:221.

20. Langenberg C, Bagshaw SM, May CN, Bellomo R (2008) The histopathology of septic acute kidney injury: a systematic review. Crit Care 12:R38.

21. Lerolle N, Nochy D, Guerot E, Bruneval P, Fagon JY, Diehl JL, Hill G (2010) Histopathology of septic shock induced acute kidney injury: apoptosis and leukocytic infiltration. Intensive Care Med 36:471-478.

22. Nourbakhsh N, Singh P (2014) Role of renal oxygenation and mitochondrial function in the pathophysiology of acute kidney injury. Nephron Clin Pract 127:149-152.

23. Bellomo R, Ronco C, Kellum JA, Mehta RL, Palevsky P (2004) Acute renal failure definition, outcome measures, animal models, fluid therapy and information technology needs: the Second International Consensus Conference of the Acute Dialysis Quality Initiative (ADQI) Group. Crit Care 8:R204-R212.

24. Mehta RL, Kellum JA, Shah SV, Molitoris BA, Ronco C, Warnock DG, Levin A (2007) Acute Kidney Injury Network: report of an initiative to improve outcomes in acute kidney injury. Crit Care 11:R31.

25. Kidney Disease: Improving Global Outcomes (KDIGO) Acute Kidney Injury Work Group (2013) KDIGO clinical practice guideline for acute kidney injury. Kidney Int Suppl.2:1-138.

26. Molnar AO, Yuen DA, Tangri N, Jensen VL (2014) Bridging the gap: a Canadian perspective on translational kidney research. Canadian journal of kidney health and disease 1:18.

27. Meran S, Wonnacott A, Amphlett B, Phillips A (2014) How good are we at managing acute kidney injury in hospital? Clinical kidney journal 7:144-150.

28. Brusselaers N, Monstrey S, Colpaert K, Decruyenaere J, Blot SI, Hoste EA (2010) Outcome of acute kidney injury in severe burns: a systematic review and metaanalysis. Intensive Care Med 36:915-925.

29. Yilmaz R, Erdem Y (2010) Acute kidney injury in the elderly population. Int Urol Nephrol 42:259-271.

30. Liu Y, Davari-Farid S, Arora P, Porhomayon J, Nader ND (2014) Early versus late initiation of renal replacement therapy in critically ill patients with acute kidney injury after cardiac surgery: a systematic review and meta-analysis. J Cardiothorac Vasc Anesth 28:557-563.

31. Mutter TC, Ruth CA, Dart AB (2013) Hydroxyethyl starch (HES) versus other fluid therapies: effects on kidney function. The Cochrane database of systematic reviews 7:CD007594.

32. Yang B, Xu J, Xu F, Zou Z, Ye C, Mei C, Mao Z (2014) Intravascular administration of mannitol for acute kidney injury prevention: a systematic review and meta-analysis. PLoS One 9:e85029.

33. Zeng X, Zhang L, Wu T, Fu P (2014) Continuous renal replacement therapy (CRRT) for rhabdomyolysis. The Cochrane database of systematic reviews 6:CD008566.

34. Jun M, Heerspink HJ, Ninomiya T, Gallagher M, Bellomo R, Myburgh J, Finfer S, Palevsky PM, Kellum JA, Perkovic V, Cass A (2010) Intensities of renal replacement therapy in acute kidney injury: a systematic review and meta-analysis. Clin J Am Soc Nephrol 5:956-963. 
35. Vesconi S, Cruz DN, Fumagalli R, Kindgen-Milles D, Monti G, Marinho A, Mariano F, Formica M, Marchesi M, Rene R, Livigni S, Ronco C (2009) Delivered dose of renal replacement therapy and mortality in critically ill patients with acute kidney injury. Crit Care 13:R57.

36. Dennen P, Parikh CR (2007) Biomarkers of acute kidney injury: can we replace serum creatinine? Clin Nephrol 68:269-278.

37. Slocum JL, Heung M, Pennathur S (2012) Marking renal injury: can we move beyond serum creatinine? Transl Res 159:277-289.

38. Gonzalez F, Vincent F (2012) Biomarkers for acute kidney injury in critically ill patients. Minerva Anestesiol 78:1394-1403.

39. Vanmassenhove J, Vanholder R, Nagler E, Van Biesen W (2013) Urinary and serum biomarkers for the diagnosis of acute kidney injury: an in-depth review of the literature. Nephrol Dial Transplant 28:254-273.

40. Dowdy DW, Eid MP, Sedrakyan A, Mendez-Tellez PA, Pronovost PJ, Herridge MS, Needham DM (2005) Quality of life in adult survivors of critical illness: a systematic review of the literature. Intensive Care Med 31:611-620.

41. Turnbull AE, Rabiee A, Davis WE, Nasser MF, Venna VR, Lolitha R, Hopkins RO, Bienvenu OJ, Robinson KA, Needham DM (2016) Outcome Measurement in ICU Survivorship Research From 1970 to 2013: A Scoping Review of 425 Publications. Crit Care Med 44:1267-1277.

42. Wunsch H, Angus DC, Harrison DA, Collange O, Fowler R, Hoste EA, de Keizer NF, Kersten A, Linde-Zwirble WT, Sandiumenge A, Rowan KM (2008) Variation in critical care services across North America and Western Europe. Crit Care Med 36:2787-2793.

43. Austin S, Murthy S, Wunsch H, Adhikari NK, Karir V, Rowan K, Jacob ST, Salluh J, Bozza FA, Du B, An Y, Lee B, Wu F, Nguyen YL, Oppong C, Venkataraman R, Velayutham V, Duenas C, Angus DC (2014) Access to urban acute care services in high- vs. middle-income countries: an analysis of seven cities. Intensive Care Med 40:342-352.

44. Le Gall JR, Lemeshow S, Saulnier F (1993) A new Simplified Acute Physiology Score (SAPS II) based on a European/North American multicenter study. JAMA 270:2957-2963.

45. Vincent JL, de Mendonca A, Cantraine F, Moreno R, Takala J, Suter PM, Sprung CL, Colardyn F, Blecher S (1998) Use of the SOFA score to assess the incidence of organ dysfunction/failure in intensive care units: results of a multicenter, prospective study. Working group on "sepsis-related problems" of the European Society of Intensive Care Medicine. Crit Care Med 26:1793-1800.

46. Polinder S, Haagsma JA, Toet H, Brugmans MJ, van Beeck EF (2010) Burden of injury in childhood and adolescence in 8 European countries. BMC Public Health $10: 45$.

47. Soreide K (2009) Epidemiology of major trauma. Br J Surg 96:697-698.

48. Baker SP, O'Neill B, Haddon W, Jr., Long WB (1974) The injury severity score: a method for describing patients with multiple injuries and evaluating emergency care. $\mathrm{J}$ Trauma 14:187-196. 
49. Kortbeek JB, Al Turki SA, Ali J, Antoine JA, Bouillon B, Brasel K, Brenneman F, Brink PR, Brohi K, Burris D, Burton RA, Chapleau W, Cioffi W, Collet e Silva Fde S, Cooper A, Cortes JA, Eskesen V, Fildes J, Gautam S, Gruen RL, Gross R, Hansen KS, Henny W, Hollands MJ, Hunt RC, Jover Navalon JM, Kaufmann CR, Knudson P, Koestner A, Kosir R, Larsen CF, Livaudais W, Luchette F, Mao P, McVicker JH, Meredith JW, Mock C, Mori ND, Morrow C, Parks SN, Pereira PM, Pogetti RS, Ravn J, Rhee P, Salomone JP, Schipper IB, Schoettker P, Schreiber MA, Smith RS, Svendsen LB, Taha W, van Wijngaarden-Stephens M, Varga E, Voiglio EJ, Williams D, Winchell RJ, Winter R (2008) Advanced trauma life support, 8th edition, the evidence for change. J Trauma 64:1638-1650.

50. Rossaint R, Bouillon B, Cerny V, Coats TJ, Duranteau J, Fernandez-Mondejar E, Filipescu D, Hunt BJ, Komadina R, Nardi G, Neugebauer EA, Ozier Y, Riddez L, Schultz A, Vincent JL, Spahn DR (2016) The European guideline on management of major bleeding and coagulopathy following trauma: fourth edition. Crit Care 20:100.

51. Bihorac A, Delano MJ, Schold JD, Lopez MC, Nathens AB, Maier RV, Layon AJ, Baker HV, Moldawer LL (2010) Incidence, clinical predictors, genomics, and outcome of acute kidney injury among trauma patients. Ann Surg 252:158-165.

52. Lehmann U, Grotz M, Regel G, Rudolph S, Tscherne H (1995) [Does initial management of polytrauma patients have an effect on the development of multiple organ failure? Evaluation of preclinical and clinical data of 1,112 polytrauma patients]. Unfallchirurg 98:442-446.

53. de Abreu KL, Silva Junior GB, Barreto AG, Melo FM, Oliveira BB, Mota RM, Rocha NA, Silva SL, Araujo SM, Daher EF (2010) Acute kidney injury after trauma: Prevalence, clinical characteristics and RIFLE classification. Indian J Crit Care Med 14:121-128.

54. Skinner DL, Hardcastle TC, Rodseth RN, Muckart DJ (2014) The incidence and outcomes of acute kidney injury amongst patients admitted to a level I trauma unit. Injury 45:259-264.

55. Santos PR, Monteiro DL (2015) Acute kidney injury in an intensive care unit of a general hospital with emergency room specializing in trauma: an observational prospective study. BMC Nephrol 16:30.

56. Eriksson M, Brattstrom O, Martensson J, Larsson E, Oldner A (2015) Acute kidney injury following severe trauma: Risk factors and long-term outcome. The journal of trauma and acute care surgery 79:407-412.

57. Shashaty MG, Meyer NJ, Localio AR, Gallop R, Bellamy SL, Holena DN, Lanken PN, Kaplan S, Yarar D, Kawut SM, Feldman HI, Christie JD (2012) African American race, obesity, and blood product transfusion are risk factors for acute kidney injury in critically ill trauma patients. J Crit Care 27:496-504.

58. Talving P, Karamanos E, Skiada D, Lam L, Teixeira PG, Inaba K, Johnson J, Demetriades D (2013) Relationship of creatine kinase elevation and acute kidney injury in pediatric trauma patients. The journal of trauma and acute care surgery 74:912-916.

59. He M, Li S, Sang X, Liu J (2014) [The incidence and risk factors of acute renal injury in patients with multiple soft tissue injuries]. Zhonghua Nei Ke Za Zhi 53:174-177.

60. Bagshaw SM, George C, Gibney RT, Bellomo R (2008) A multi-center evaluation of early acute kidney injury in critically ill trauma patients. Ren Fail 30:581-589.

61. Ala-Kokko T, Ohtonen P, Laurila J, Martikainen M, Kaukoranta P (2006) Development of renal failure during the initial $24 \mathrm{~h}$ of intensive care unit stay correlates with hospital mortality in trauma patients. Acta Anaesthesiol Scand 50:828832. 
62. Rivara FP, Mackenzie EJ, Jurkovich GJ, Nathens AB, Wang J, Scharfstein DO (2008) Prevalence of pain in patients 1 year after major trauma. Arch Surg 143:282-287.

63. Ulvik A, Kvale R, Wentzel-Larsen T, Flaatten H (2008) Quality of life 2-7 years after major trauma. Acta Anaesthesiol Scand 52:195-201.

64. Zipes DP, Wellens HJ (1998) Sudden cardiac death. Circulation 98:2334-2351.

65. Zheng ZJ, Croft JB, Giles WH, Mensah GA (2001) Sudden cardiac death in the United States, 1989 to 1998. Circulation 104:2158-2163.

66. Grasner JT, Lefering R, Koster RW, Masterson S, Bottiger BW, Herlitz J, Wnent J, Tjelmeland IB, Ortiz FR, Maurer H, Baubin M, Mols P, Hadzibegovic I, Ioannides M, Skulec R, Wissenberg M, Salo A, Hubert H, Nikolaou NI, Loczi G, Svavarsdottir H, Semeraro F, Wright PJ, Clarens C, Pijls R, Cebula G, Correia VG, Cimpoesu D, Raffay V, Trenkler S, Markota A, Stromsoe A, Burkart R, Perkins GD, Bossaert LL (2016) EuReCa ONE-27 Nations, ONE Europe, ONE Registry: A prospective one month analysis of out-of-hospital cardiac arrest outcomes in 27 countries in Europe. Resuscitation 105:188-195.

67. Goldberger JJ, Cain ME, Hohnloser SH, Kadish AH, Knight BP, Lauer MS, Maron BJ, Page RL, Passman RS, Siscovick D, Stevenson WG, Zipes DP (2008) American Heart Association/american College of Cardiology Foundation/heart Rhythm Society scientific statement on noninvasive risk stratification techniques for identifying patients at risk for sudden cardiac death: a scientific statement from the American Heart Association Council on Clinical Cardiology Committee on Electrocardiography and Arrhythmias and Council on Epidemiology and Prevention. Heart Rhythm 5:e121.

68. Sans S, Kesteloot H, Kromhout D (1997) The burden of cardiovascular diseases mortality in Europe. Task Force of the European Society of Cardiology on Cardiovascular Mortality and Morbidity Statistics in Europe. Eur Heart J 18:12311248.

69. Engdahl J, Holmberg M, Karlson BW, Luepker R, Herlitz J (2002) The epidemiology of out-of-hospital 'sudden' cardiac arrest. Resuscitation 52:235-245.

70. Holmberg M, Holmberg S, Herlitz J (2000) Incidence, duration and survival of ventricular fibrillation in out-of-hospital cardiac arrest patients in sweden.

Resuscitation 44:7-17.

71. Zive D, Koprowicz K, Schmidt T, Stiell I, Sears G, Van Ottingham L, Idris A, Stephens S, Daya M (2011) Variation in out-of-hospital cardiac arrest resuscitation and transport practices in the Resuscitation Outcomes Consortium: ROC EpistryCardiac Arrest. Resuscitation 82:277-284.

72. Bunch TJ, Hammill SC, White RD (2005) Outcomes after ventricular fibrillation outof-hospital cardiac arrest: expanding the chain of survival. Mayo Clin Proc 80:774782.

73. Nolan JP, Soar J, Cariou A, Cronberg T, Moulaert VR, Deakin CD, Bottiger BW, Friberg H, Sunde K, Sandroni C (2015) European Resuscitation Council and European Society of Intensive Care Medicine Guidelines for Post-resuscitation Care 2015: Section 5 of the European Resuscitation Council Resuscitation Guidelines 2015. Resuscitation 95:202-222.

74. Sunde K, Pytte M, Jacobsen D, Mangschau A, Jensen LP, Smedsrud C, Draegni T, Steen PA (2007) Implementation of a standardised treatment protocol for post resuscitation care after out-of-hospital cardiac arrest. Resuscitation 73:29-39.

75. Tomte O, Andersen GO, Jacobsen D, Draegni T, Auestad B, Sunde K (2011) Strong and weak aspects of an established post-resuscitation treatment protocol-A five-year observational study. Resuscitation 82:1186-1193. 
76. Deasy C, Bray JE, Smith K, Harriss LR, Bernard SA, Cameron P (2011) Out-ofhospital cardiac arrests in the older age groups in Melbourne, Australia. Resuscitation 82:398-403.

77. Nichol G, Thomas E, Callaway CW, Hedges J, Powell JL, Aufderheide TP, Rea T, Lowe R, Brown T, Dreyer J, Davis D, Idris A, Stiell I (2008) Regional variation in out-of-hospital cardiac arrest incidence and outcome. JAMA 300:1423-1431.

78. Neumar RW, Nolan JP, Adrie C, Aibiki M, Berg RA, Bottiger BW, Callaway C, Clark RS, Geocadin RG, Jauch EC, Kern KB, Laurent I, Longstreth WT, Jr., Merchant RM, Morley P, Morrison LJ, Nadkarni V, Peberdy MA, Rivers EP, Rodriguez-Nunez A, Sellke FW, Spaulding C, Sunde K, Vanden Hoek T (2008) Post-cardiac arrest syndrome: epidemiology, pathophysiology, treatment, and prognostication. A consensus statement from the International Liaison Committee on Resuscitation (American Heart Association, Australian and New Zealand Council on Resuscitation, European Resuscitation Council, Heart and Stroke Foundation of Canada, InterAmerican Heart Foundation, Resuscitation Council of Asia, and the Resuscitation Council of Southern Africa); the American Heart Association Emergency Cardiovascular Care Committee; the Council on Cardiovascular Surgery and Anesthesia; the Council on Cardiopulmonary, Perioperative, and Critical Care; the Council on Clinical Cardiology; and the Stroke Council. Circulation 118:2452-2483.

79. Roberts BW, Kilgannon JH, Chansky ME, Mittal N, Wooden J, Parrillo JE, Trzeciak S (2013) Multiple organ dysfunction after return of spontaneous circulation in postcardiac arrest syndrome. Crit Care Med 41:1492-1501.

80. Domanovits H, Schillinger M, Mullner M, Thoennissen J, Sterz F, Zeiner A, Druml W (2001) Acute renal failure after successful cardiopulmonary resuscitation. Intensive Care Med 27:1194-1199.

81. Geri G, Guillemet L, Dumas F, Charpentier J, Antona M, Lemiale V, Bougouin W, Lamhaut L, Mira JP, Vinsonneau C, Cariou A (2015) Acute kidney injury after out-ofhospital cardiac arrest: risk factors and prognosis in a large cohort. Intensive Care Med 41:1273-1280.

82. Hasper D, von HS, Storm C, Jorres A, Schefold JC (2009) Changes in serum creatinine in the first 24 hours after cardiac arrest indicate prognosis: an observational cohort study. Crit Care 13:R168.

83. Mattana J, Singhal PC (1993) Prevalence and determinants of acute renal failure following cardiopulmonary resuscitation. Arch Intern Med 153:235-239.

84. Tujjar O, Mineo G, Dell'Anna A, Poyatos-Robles B, Donadello K, Scolletta S, Vincent JL, Taccone FS (2015) Acute kidney injury after cardiac arrest. Crit Care 19:169.

85. Sandroni C, Dell'anna AM, Tujjar O, Geri G, Cariou A, Taccone FS (2016) Acute Kidney Injury (AKI) after cardiac arrest: a systematic review and meta-analysis of clinical studies. Minerva Anestesiol 82:989-999.

86. Yanta J, Guyette FX, Doshi AA, Callaway CW, Rittenberger JC (2013) Renal dysfunction is common following resuscitation from out-of-hospital cardiac arrest. Resuscitation 84:1371-1374.

87. Jennett B, Bond M (1975) Assessment of outcome after severe brain damage. Lancet $1: 480-484$.

88. Castren M, Karlsten R, Lippert F, Christensen EF, Bovim E, Kvam AM, RobertsonSteel I, Overton J, Kraft T, Engerstrom L, Garcia-Castrill RL (2008) Recommended guidelines for reporting on emergency medical dispatch when conducting research in emergency medicine: the Utstein style. Resuscitation 79:193-197. 
89. Murray PT, Mehta RL, Shaw A, Ronco C, Endre Z, Kellum JA, Chawla LS, Cruz D, Ince C, Okusa MD (2014) Potential use of biomarkers in acute kidney injury: report and summary of recommendations from the 10th Acute Dialysis Quality Initiative consensus conference. Kidney Int 85:513-521.

90. Kidney Disease: Improving Global Outcomes (KDIGO) Chronic kidney disease work group (2013) KDIGO clinical practice guideline for the evaluation and management of chronic kidney disease. Kidney Int Suppl. 3:1-150.

91. Novis BK, Roizen MF, Aronson S, Thisted RA (1994) Association of preoperative risk factors with postoperative acute renal failure. Anesth Analg 78:143-149.

92. Hoste EA, Clermont G, Kersten A, Venkataraman R, Angus DC, De Bacquer D, Kellum JA (2006) RIFLE criteria for acute kidney injury are associated with hospital mortality in critically ill patients: a cohort analysis. Crit Care 10:R73.

93. Hsu CY, McCulloch CE, Fan D, Ordonez JD, Chertow GM, Go AS (2007) Community-based incidence of acute renal failure. Kidney Int 72:208-212.

94. Waikar SS, Curhan GC, Wald R, McCarthy EP, Chertow GM (2006) Declining mortality in patients with acute renal failure, 1988 to 2002. J Am Soc Nephrol 17:1143-1150.

95. Siew ED, Davenport A (2015) The growth of acute kidney injury: a rising tide or just closer attention to detail? Kidney Int 87:46-61.

96. Lewington AJ, Cerda J, Mehta RL (2013) Raising awareness of acute kidney injury: a global perspective of a silent killer. Kidney Int 84:457-467.

97. McMillan M, Mactier R (2011) Precipitating factors and patient outcomes in acute kidney injury treated with renal replacement therapy. Scott Med J 56:30-32.

98. Li X, Hassoun HT, Santora R, Rabb H (2009) Organ crosstalk: the role of the kidney. Curr Opin Crit Care 15:481-487.

99. Shenfeld OZ, Gnessin E (2011) Management of urogenital trauma: state of the art. Current opinion in urology 21:449-454.

100. Singh O, Gupta SS, Sharma D, Lahoti BK, Mathur RK (2011) Isolated renal artery thrombosis because of blunt trauma abdomen: report of a case with review of the literature. Urol Int 86:233-238.

101. Patel DM, Connor MJ, Jr. (2016) Intra-Abdominal Hypertension and Abdominal Compartment Syndrome: An Underappreciated Cause of Acute Kidney Injury. Adv Chronic Kidney Dis 23:160-166.

102. Ortega SJ, Netto FS, Hamilton P, Chu P, Tien HC (2008) CT scanning for diagnosing blunt ureteral and ureteropelvic junction injuries. BMC Urol 8:3.

103. Basile DP, Anderson MD, Sutton TA (2012) Pathophysiology of acute kidney injury. Comprehensive Physiology 2:1303-1353.

104. Yap SC, Lee HT (2012) Acute kidney injury and extrarenal organ dysfunction: new concepts and experimental evidence. Anesthesiology 116:1139-1148.

105. Heywood JT, Fonarow GC, Costanzo MR, Mathur VS, Wigneswaran JR, Wynne J (2007) High prevalence of renal dysfunction and its impact on outcome in 118,465 patients hospitalized with acute decompensated heart failure: a report from the ADHERE database. J Card Fail 13:422-430.

106. McCullough PA, Kellum JA, Haase M, Muller C, Damman K, Murray PT, Cruz D, House AA, Schmidt-Ott KM, Vescovo G, Bagshaw SM, Hoste EA, Briguori C, Braam B, Chawla LS, Costanzo MR, Tumlin JA, Herzog CA, Mehta RL, Rabb H, Shaw AD, Singbartl K, Ronco C (2013) Pathophysiology of the cardiorenal syndromes: executive summary from the eleventh consensus conference of the Acute Dialysis Quality Initiative (ADQI). Contrib Nephrol 182:82-98. 
107. Bagshaw SM, George C, Bellomo R (2007) Changes in the incidence and outcome for early acute kidney injury in a cohort of Australian intensive care units. Crit Care 11:R68.

108. Levy EM, Viscoli CM, Horwitz RI (1996) The effect of acute renal failure on mortality. A cohort analysis. JAMA 275:1489-1494.

109. Grams ME, Rabb H (2012) The distant organ effects of acute kidney injury. Kidney Int 81:942-948.

110. Wohlauer MV, Sauaia A, Moore EE, Burlew CC, Banerjee A, Johnson J (2012) Acute kidney injury and posttrauma multiple organ failure: the canary in the coal mine. The journal of trauma and acute care surgery 72:373-378.

111. Bihorac A, Baslanti TO, Cuenca AG, Hobson CE, Ang D, Efron PA, Maier RV, Moore FA, Moldawer LL (2013) Acute kidney injury is associated with early cytokine changes after trauma. The journal of trauma and acute care surgery 74:1005-1013.

112. Li GS, Chen XL, Zhang Y, He Q, Wang F, Hong DQ, Zhang P, Pu L, Zhang Y, Yang XC, Wang L (2010) Malnutrition and inflammation in acute kidney injury due to earthquake-related crush syndrome. BMC Nephrol 11:4.

113. Bonventre JV (2010) Pathophysiology of AKI: injury and normal and abnormal repair. Contrib Nephrol 165:9-17.

114. Bonventre JV, Weinberg JM (2003) Recent advances in the pathophysiology of ischemic acute renal failure. J Am Soc Nephrol 14:2199-2210.

115. Zuk A, Bonventre JV, Brown D, Matlin KS (1998) Polarity, integrin, and extracellular matrix dynamics in the postischemic rat kidney. Am J Physiol 275:711-731.

116. May CN, Calzavacca P, Ishikawa K, Langenberg C, Wan L, Ramchandra R, Bellomo R (2012) Novel targets for sepsis-induced kidney injury: the glomerular arterioles and the sympathetic nervous system. Exp Physiol 97:1168-1177.

117. Mariano F, Cantaluppi V, Stella M, Romanazzi GM, Assenzio B, Cairo M, Biancone L, Triolo G, Ranieri VM, Camussi G (2008) Circulating plasma factors induce tubular and glomerular alterations in septic burns patients. Crit Care 12:R42.

118. Peng Y, Zhang X, Wang Y, Li S, Wang J, Liu L (2015) Overexpression of toll-like receptor 2 in glomerular endothelial cells and podocytes in septic acute kidney injury mouse model. Ren Fail 37:694-698.

119. Awad AS, Rouse M, Huang L, Vergis AL, Reutershan J, Cathro HP, Linden J, Okusa MD (2009) Compartmentalization of neutrophils in the kidney and lung following acute ischemic kidney injury. Kidney Int 75:689-698.

120. Praga M, Gonzalez E (2010) Acute interstitial nephritis. Kidney Int 77:956-961.

121. Verma SK, Molitoris BA (2015) Renal endothelial injury and microvascular dysfunction in acute kidney injury. Semin Nephrol 35:96-107.

122. Lu JC, Coca SG, Patel UD, Cantley L, Parikh CR (2009) Searching for genes that matter in acute kidney injury: a systematic review. Clin J Am Soc Nephrol 4:10201031.

123. Haase-Fielitz A, Haase M, Bellomo R, Dragun D (2007) Genetic polymorphisms in sepsis- and cardiopulmonary bypass-associated acute kidney injury. Contrib Nephrol 156:75-91.

124. Elmer J, Jeong K, Abebe KZ, Guyette FX, Murugan R, Callaway CW, Rittenberger JC (2016) Serum Neutrophil Gelatinase-Associated Lipocalin Predicts Survival After Resuscitation From Cardiac Arrest. Crit Care Med 44:111-119.

125. Halladin NL (2015) Oxidative and inflammatory biomarkers of ischemia and reperfusion injuries. Dan Med J 62:B5054.

126. Pattharanitima P, Tasanarong A (2014) Pharmacological strategies to prevent contrastinduced acute kidney injury. BioMed research international 2014:236930. 
127. Bagshaw SM, Delaney A, Haase M, Ghali WA, Bellomo R (2007) Loop diuretics in the management of acute renal failure: a systematic review and meta-analysis. Crit Care Resusc 9:60-68.

128. Bellomo R, Chapman M, Finfer S, Hickling K, Myburgh J (2000) Low-dose dopamine in patients with early renal dysfunction: a placebo-controlled randomised trial. Australian and New Zealand Intensive Care Society (ANZICS) Clinical Trials Group. Lancet 356:2139-2143.

129. Bellomo R, Giantomasso DD (2001) Noradrenaline and the kidney: friends or foes? Crit Care 5:294-298.

130. Birck R, Krzossok S, Markowetz F, Schnulle P, van der Woude FJ, Braun C (2003) Acetylcysteine for prevention of contrast nephropathy: meta-analysis. Lancet 362:598603.

131. Brown CV, Rhee P, Chan L, Evans K, Demetriades D, Velmahos GC (2004) Preventing renal failure in patients with rhabdomyolysis: do bicarbonate and mannitol make a difference? J Trauma 56:1191-1196.

132. Friedrich JO, Adhikari N, Herridge MS, Beyene J (2005) Meta-analysis: low-dose dopamine increases urine output but does not prevent renal dysfunction or death. Ann Intern Med 142:510-524.

133. Ho KM, Sheridan DJ (2006) Meta-analysis of frusemide to prevent or treat acute renal failure. BMJ 333:420.

134. Kellum JA, J MD (2001) Use of dopamine in acute renal failure: a meta-analysis. Crit Care Med 29:1526-1531.

135. Landoni G, Biondi-Zoccai GG, Tumlin JA, Bove T, De Luca M, Calabro MG, Ranucci M, Zangrillo A (2007) Beneficial impact of fenoldopam in critically ill patients with or at risk for acute renal failure: a meta-analysis of randomized clinical trials. Am J Kidney Dis 49:56-68.

136. Zacharias M, Mugawar M, Herbison GP, Walker RJ, Hovhannisyan K, Sivalingam P, Conlon NP (2013) Interventions for protecting renal function in the perioperative period. The Cochrane database of systematic reviews 9:CD003590.

137. Joannidis M, Druml W, Forni LG, Groeneveld AB, Honore P, Oudemans-van Straaten HM, Ronco C, Schetz MR, Woittiez AJ (2010) Prevention of acute kidney injury and protection of renal function in the intensive care unit. Expert opinion of the Working Group for Nephrology, ESICM. Intensive Care Med 36:392-411.

138. Petejova N, Martinek A (2014) Acute kidney injury due to rhabdomyolysis and renal replacement therapy: a critical review. Crit Care 18:224.

139. Panizo N, Rubio-Navarro A, Amaro-Villalobos JM, Egido J, Moreno JA (2015) Molecular Mechanisms and Novel Therapeutic Approaches to RhabdomyolysisInduced Acute Kidney Injury. Kidney Blood Press Res 40:520-532.

140. Mårtensson J (2011) Biomarkers of Acute Kidney injury. Thesis for doctoral degree. Karolinska Institutet, Stockholm, Sweeden. 1-70.

141. Carlier M, Dumoulin A, Janssen A, Picavet S, Vanthuyne S, Van Eynde R, Vanholder R, Delanghe J, De Schoenmakere G, De Waele JJ, Hoste EA (2015) Comparison of different equations to assess glomerular filtration in critically ill patients. Intensive Care Med 41:427-435. 
142. Kashani K, Al-Khafaji A, Ardiles T, Artigas A, Bagshaw SM, Bell M, Bihorac A, Birkhahn R, Cely CM, Chawla LS, Davison DL, Feldkamp T, Forni LG, Gong MN, Gunnerson KJ, Haase M, Hackett J, Honore PM, Hoste EA, Joannes-Boyau O, Joannidis M, Kim P, Koyner JL, Laskowitz DT, Lissauer ME, Marx G, McCullough PA, Mullaney S, Ostermann M, Rimmele T, Shapiro NI, Shaw AD, Shi J, Sprague AM, Vincent JL, Vinsonneau C, Wagner L, Walker MG, Wilkerson RG, Zacharowski K, Kellum JA (2013) Discovery and validation of cell cycle arrest biomarkers in human acute kidney injury. Crit Care 17:R25.

143. Chawla LS, Goldstein SL, Kellum JA, Ronco C (2015) Renal angina: concept and development of pretest probability assessment in acute kidney injury. Crit Care 19:93.

144. Safari S, Yousefifard M, Hashemi B, Baratloo A, Forouzanfar MM, Rahmati F, Motamedi M, Najafi I (2016) The value of serum creatine kinase in predicting the risk of rhabdomyolysis-induced acute kidney injury: a systematic review and metaanalysis. Clin Exp Nephrol 20:153-161.

145. Balasubramanian G, Al-Aly Z, Moiz A, Rauchman M, Zhang Z, Gopalakrishnan R, Balasubramanian S, El-Achkar TM (2011) Early nephrologist involvement in hospitalacquired acute kidney injury: a pilot study. Am J Kidney Dis 57:228-234.

146. Uchino S, Bellomo R, Morimatsu H, Morgera S, Schetz M, Tan I, Bouman C, Macedo E, Gibney N, Tolwani A, Oudemans-van SH, Ronco C, Kellum JA (2007) Continuous renal replacement therapy: a worldwide practice survey. The beginning and ending supportive therapy for the kidney (B.E.S.T. kidney) investigators. Intensive Care Med 33:1563-1570.

147. Gatward JJ, Gibbon GJ, Wrathall G, Padkin A (2008) Renal replacement therapy for acute renal failure: a survey of practice in adult intensive care units in the United Kingdom. Anaesthesia 63:959-966.

148. RENAL study investigators (2008) Renal replacement therapy for acute kidney injury in Australian and New Zealand intensive care units: a practice survey. Crit Care Resusc 10:225-230.

149. Gaudry S, Hajage D, Schortgen F, Martin-Lefevre L, Pons B, Boulet E, Boyer A, Chevrel G, Lerolle N, Carpentier D, de Prost N, Lautrette A, Brtagnol A, Mayaux J, Nseir S, Megarbane B, Thirion M, Forel JM, Maizel J, Yonis H, Markowicz P, Thiery G, Tubach F, Ricard JD, Dreyfuss D; AKIKI Study Group (2016) Initiation Strategies for Renal-Replacement Therapy in the Intensive Care Unit. N Engl J Med 375:122-133.

150. Zarbock A, Kellum JA, Schmidt C, Van Aken H, Wempe C, Pavenstädt H, Boanta A, Gerß J, Meersch M (2016) Effect of Early vs Delayed Initiation of Renal Replacement Therapy on Mortality in Critically Ill Patients With Acute Kidney Injury: The ELAIN Randomized Clinical Trial. JAMA. 2016 May 24-31;315(20):2190-2199.

151. Sugahara S, Suzuki H (2004) Early start on continuous hemodialysis therapy improves survival rate in patients with acute renal failure following coronary bypass surgery. Hemodialysis international International Symposium on Home Hemodialysis 8:320325.

152. Karvellas CJ, Farhat MR, Sajjad I, Mogensen SS, Leung AA, Wald R, Bagshaw SM (2011) A comparison of early versus late initiation of renal replacement therapy in critically ill patients with acute kidney injury: a systematic review and meta-analysis. Crit Care 15:R72.

153. Rabindranath K, Adams J, Macleod AM, Muirhead N (2007) Intermittent versus continuous renal replacement therapy for acute renal failure in adults. The Cochrane database of systematic reviews:CD003773. 
154. Ghahramani N, Shadrou S, Hollenbeak C (2008) A systematic review of continuous renal replacement therapy and intermittent haemodialysis in management of patients with acute renal failure. Nephrology 13:570-578.

155. Pannu N, Klarenbach S, Wiebe N, Manns B, Tonelli M (2008) Renal replacement therapy in patients with acute renal failure: a systematic review. JAMA 299:793-805.

156. Schneider AG, Bellomo R, Bagshaw SM, Glassford NJ, Lo S, Jun M, Cass A, Gallagher M (2013) Choice of renal replacement therapy modality and dialysis dependence after acute kidney injury: a systematic review and meta-analysis. Intensive Care Med 39:987-997.

157. Ethgen O, Schneider AG, Bagshaw SM, Bellomo R, Kellum JA (2015) Economics of dialysis dependence following renal replacement therapy for critically ill acute kidney injury patients. Nephrol Dial Transplant 30:54-61.

158. Wald R, Friedrich JO, Bagshaw SM, Burns KE, Garg AX, Hladunewich MA, House AA, Lapinsky S, Klein D, Pannu NI, Pope K, Richardson RM, Thorpe K, Adhikari NK (2012) Optimal Mode of clearance in critically ill patients with Acute Kidney Injury (OMAKI)--a pilot randomized controlled trial of hemofiltration versus hemodialysis: a Canadian Critical Care Trials Group project. Crit Care 16:R205.

159. Friedrich JO, Wald R, Bagshaw SM, Burns KE, Adhikari NK (2012) Hemofiltration compared to hemodialysis for acute kidney injury: systematic review and metaanalysis. Crit Care 16:R146.

160. Claure-Del Granado R, Mehta RL (2011) Assessing and delivering dialysis dose in acute kidney injury. Seminars in dialysis 24:157-163.

161. Negash DT, Dhingra VK, Copland M, Griesdale D, Henderson W (2011) Intensity of continuous renal replacement therapy in acute kidney injury in the intensive care unit: a systematic review and meta-analysis. Vasc Endovascular Surg 45:504-510.

162. Casey ET, Gupta BP, Erwin PJ, Montori VM, Murad MH (2010) The dose of continuous renal replacement therapy for acute renal failure: a systematic review and meta-analysis. Ren Fail 32:555-561.

163. Claure-Del Granado R, Mehta RL (2011) Withholding and withdrawing renal support in acute kidney injury. Seminars in dialysis 24:208-214.

164. Leberle R, Ernstberger A, Loibl M, Merkl J, Bunz M, Creutzenberg M, Trabold B (2015) Association of high volumes of hydroxyethyl starch with acute kidney injury in elderly trauma patients. Injury 46:105-109.

165. Srisawat N, Loredo Lawsin L, Uchino S, Bellomo R, Kellum JA, BEST Kidney Investigators (2010) Cost of acute renal replacement therapy in the intensive care unit: results from The Beginning and Ending Supportive Therapy for the Kidney (BEST Kidney) Study. Crit Care 14: R46.

166. Marshall JC, Cook DJ, Christou NV, Bernard GR, Sprung CL, Sibbald WJ (1995) Multiple organ dysfunction score: a reliable descriptor of a complex clinical outcome. Crit Care Med 23:1638-1652.

167. Bellomo R (2006) The epidemiology of acute renal failure: 1975 versus 2005. Curr Opin Crit Care 12:557-560.

168. Sigurdsson MI, Vesteinsdottir IO, Sigvaldason K, Helgadottir S, Indridason OS, Sigurdsson GH (2012) Acute kidney injury in intensive care units according to RIFLE classification: a population-based study. Acta Anaesthesiol Scand 56:1291-1297.

169. Rimes-Stigare C, Frumento P, Bottai M, Martensson J, Martling CR, Bell M (2015) Long-term mortality and risk factors for development of end-stage renal disease in critically ill patients with and without chronic kidney disease. Crit Care 19:383. 
170. Coca SG, Singanamala S, Parikh CR (2012) Chronic kidney disease after acute kidney injury: a systematic review and meta-analysis. Kidney Int 81:442-448.

171. Villeneuve PM, Clark EG, Sikora L, Sood MM, Bagshaw SM (2016) Health-related quality-of-life among survivors of acute kidney injury in the intensive care unit: a systematic review. Intensive Care Med 42:137-146.

172. Champion HR, Sacco WJ, Copes WS, Gann DS, Gennarelli TA, Flanagan ME (1989) A revision of the Trauma Score. J Trauma 29:623-629.

173. Bone RC, Balk RA, Cerra FB, Dellinger RP, Fein AM, Knaus WA, Schein RM, Sibbald WJ (1992) Definitions for sepsis and organ failure and guidelines for the use of innovative therapies in sepsis. The ACCP/SCCM Consensus Conference Committee. American College of Chest Physicians/Society of Critical Care Medicine. Chest 101:1644-1655.

174. Beitland S TA, Brusletto BS, Berg JP, Waldum-Grevbo B, Sunde K (2016) Stability of urinary biomarkers of acute kidney injury. Intensive Care Medicine Experimental $4: 30$.

175. van de Vrie M, Deegens JK, van der Vlag J, Hilbrands LB (2014) Effect of long-term storage of urine samples on measurement of kidney injury molecule 1 (KIM-1) and neutrophil gelatinase-associated lipocalin (NGAL). Am J Kidney Dis 63:573-576.

176. Parikh CR, Butrymowicz I, Yu A, Chinchilli VM, Park M, Hsu CY, Reeves WB, Devarajan P, Kimmel PL, Siew ED, Liu KD (2014) Urine stability studies for novel biomarkers of acute kidney injury. Am J Kidney Dis 63:567-572.

177. Morris JA, Jr., Mucha P, Jr., Ross SE, Moore BF, Hoyt DB, Gentilello L, Landercasper J, Feliciano DV, Shackford SR (1991) Acute posttraumatic renal failure: a multicenter perspective. J Trauma 31(12):1584-1590.

178. Brown CV, Dubose JJ, Hadjizacharia P, Yanar H, Salim A, Inaba K, Rhee P, Chan L, Demetriades D (2008) Natural history and outcomes of renal failure after trauma. J Am Coll Surg 206:426-431.

179. Beitland S, Moen H, Os I (2010) Acute kidney injury with renal replacement therapy in trauma patients. Acta Anaesthesiol Scand 54:833-840.

180. Gettings LG, Reynolds HN, Scalea T (1999) Outcome in post-traumatic acute renal failure when continuous renal replacement therapy is applied early vs. late. Intensive Care Med 25:805-813.

181. Gaarder C, Dormagen JB, Eken T, Skaga NO, Klow NE, Pillgram-Larsen J, Buanes T, Naess PA (2006) Nonoperative management of splenic injuries: improved results with angioembolization. J Trauma 61:192-198.

182. Gaarder C, Naess PA, Eken T, Skaga NO, Pillgram-Larsen J, Klow NE, Buanes T (2007) Liver injuries--improved results with a formal protocol including angiography. Injury 38:1075-1083.

183. Totterman A, Dormagen JB, Madsen JE, Klow NE, Skaga NO, Roise O (2006) A protocol for angiographic embolization in exsanguinating pelvic trauma: a report on 31 patients. Acta Orthop 77:462-468.

184. Kim DY, Kobayashi L, Costantini TW, Chang D, Fortlage D, Curry T, Wynn S, Doucet J, Bansal V, Coimbra R (2012) Is contrast exposure safe among the highest risk trauma patients? The journal of trauma and acute care surgery 72:61-66.

185. McGillicuddy EA, Schuster KM, Kaplan LJ, Maung AA, Lui FY, Maerz LL, Johnson DC, Davis KA (2010) Contrast-induced nephropathy in elderly trauma patients. J Trauma 68:294-297.

186. Tremblay LN, Tien H, Hamilton P, Brenneman FD, Rizoli SB, Sharkey PW, Chu P, Rozycki GS (2005) Risk and benefit of intravenous contrast in trauma patients with an elevated serum creatinine. J Trauma 59:1162-1166. 
187. Shusterman N, Strom BL, Murray TG, Morrison G, West SL, Maislin G (1987) Risk factors and outcome of hospital-acquired acute renal failure. Clinical epidemiologic study. Am J Med 83:65-71.

188. Sykes E, Cosgrove JF (2007) Acute renal failure and the critically ill surgical patient. Ann R Coll Surg Engl 89:22-29.

189. Hotker U, Rommens PM (1996) Postrenal anuria in pelvic or acetabular injury: a report of three cases. J Trauma 41:916-919.

190. Hessmann M, Rommens P (1998) Bilateral ureteral obstruction and renal failure caused by massive retroperitoneal hematoma: is there a pelvic compartment syndrome analogous to abdominal compartment syndrome? J Orthop Trauma 12:553-557.

191. Totterman A, Madsen JE, Skaga NO, Roise O (2007) Extraperitoneal pelvic packing: a salvage procedure to control massive traumatic pelvic hemorrhage. J Trauma 62:843-852.

192. Perner A, Haase N, Guttormsen AB, Tenhunen J, Klemenzson G, Aneman A, Madsen KR, Moller MH, Elkjaer JM, Poulsen LM, Bendtsen A, Winding R, Steensen M, Berezowicz P, Soe-Jensen P, Bestle M, Strand K, Wiis J, White JO, Thornberg KJ, Quist L, Nielsen J, Andersen LH, Holst LB, Thormar K, Kjaeldgaard AL, Fabritius ML, Mondrup F, Pott FC, Moller TP, Winkel P, Wetterslev J (2012) Hydroxyethyl starch 130/0.42 versus Ringer's acetate in severe sepsis. N Engl J Med 367:124-134.

193. Zarychanski R, Abou-Setta AM, Turgeon AF, Houston BL, McIntyre L, Marshall JC, Fergusson DA (2013) Association of hydroxyethyl starch administration with mortality and acute kidney injury in critically ill patients requiring volume resuscitation: a systematic review and meta-analysis. JAMA 309:678-688.

194. Gillies MA, Habicher M, Jhanji S, Sander M, Mythen M, Hamilton M, Pearse RM (2014) Incidence of postoperative death and acute kidney injury associated with i.v. $6 \%$ hydroxyethyl starch use: systematic review and meta-analysis. $\mathrm{Br} \mathrm{J}$ Anaesth 112:25-34.

195. James MF, Michell WL, Joubert IA, Nicol AJ, Navsaria PH, Gillespie RS (2011) Resuscitation with hydroxyethyl starch improves renal function and lactate clearance in penetrating trauma in a randomized controlled study: the FIRST trial (Fluids in Resuscitation of Severe Trauma). Br J Anaesth 107:693-702.

196. Lissauer ME, Chi A, Kramer ME, Scalea TM, Johnson SB (2011) Association of 6\% hetastarch resuscitation with adverse outcomes in critically ill trauma patients. Am J Surg 202:53-58.

197. Boyd CR, Tolson MA, Copes WS (1987) Evaluating trauma care: the TRISS method. Trauma Score and the Injury Severity Score. J Trauma 27:370-378.

198. Bagshaw SM, Laupland KB, Doig CJ, Mortis G, Fick GH, Mucenski M, GodinezLuna T, Svenson LW, Rosenal T (2005) Prognosis for long-term survival and renal recovery in critically ill patients with severe acute renal failure: a population-based study. Crit Care 9:R700-R709.

199. Van Wert R, Friedrich JO, Scales DC, Wald R, Adhikari NK (2010) High-dose renal replacement therapy for acute kidney injury: Systematic review and meta-analysis. Crit Care Med 38:1360-1369.

200. Uchino S, Fealy N, Baldwin I, Morimatsu H, Bellomo R (2003) Continuous is not continuous: the incidence and impact of circuit "down-time" on uraemic control during continuous veno-venous haemofiltration. Intensive Care Med 29:575-578.

201. Beitland S, Sunde K, Moen H, Os I (2012) Variability in Uremic Control during Continuous Venovenous Hemodiafiltration in Trauma Patients. Crit Care Res Pract 2012:869237. 
202. Huerta-Alardin AL, Varon J, Marik PE (2005) Bench-to-bedside review:

Rhabdomyolysis -- an overview for clinicians. Crit Care 9:158-169.

203. Plank LD, Hill GL (2000) Sequential metabolic changes following induction of systemic inflammatory response in patients with severe sepsis or major blunt trauma. World J Surg 24:630-638.

204. Beitland S, Nakstad ER, Staer-Jensen H, Draegni T, Andersen GO, Jacobsen D, Brunborg C, Waldum-Grevbo B, Sunde K (2016) Impact of acute kidney injury on patient outcome in out-of-hospital cardiac arrest: a prospective observational study. Acta Anaesthesiol Scand 60:1170-1181.

205. Fredriksson M, Aune S, Bang A, Thoren AB, Lindqvist J, Karlsson T, Herlitz J (2010) Cardiac arrest outside and inside hospital in a community: mechanisms behind the differences in outcome and outcome in relation to time of arrest. American heart journal 159:749-756.

206. Sunde K (2013) SOPs and the right hospitals to improve outcome after cardiac arrest. Best Pract Res Clin Anaesthesiol 27:373-381.

207. Hallan SI, Coresh J, Astor BC, Asberg A, Powe NR, Romundstad S, Hallan HA, Lydersen S, Holmen J (2006) International comparison of the relationship of chronic kidney disease prevalence and ESRD risk. J Am Soc Nephrol 17:2275-2284.

208. Singbartl K, Kellum JA (2012) AKI in the ICU: definition, epidemiology, risk stratification, and outcomes. Kidney Int 81:819-825.

209. Park SO, Ahn JY, Lee YH, Kim YJ, Min YH, Ahn HC, Sohn YD, Park SM, Oh YT, Shin DH (2016) Plasma neutrophil gelatinase-associated lipocalin as an early predicting biomarker of acute kidney injury and clinical outcomes after recovery of spontaneous circulation in out-of-hospital cardiac arrest patients. Resuscitation 101:84-90.

210. Jentzer JC, Clements CM, Wright RS, White RD, Jaffe AS (2016) Improving Survival From Cardiac Arrest: A Review of Contemporary Practice and Challenges. Ann Emerg Med pii:S0196-0644.

211. Nielsen N, Sunde K, Hovdenes J, Riker RR, Rubertsson S, Stammet P, Nilsson F, Friberg H (2011) Adverse events and their relation to mortality in out-of-hospital cardiac arrest patients treated with therapeutic hypothermia. Crit Care Med 39:57-64.

212. Adrie C, Adib-Conquy M, Laurent I, Monchi M, Vinsonneau C, Fitting C, Fraisse F, Dinh-Xuan AT, Carli P, Spaulding C, Dhainaut JF, Cavaillon JM (2002) Successful cardiopulmonary resuscitation after cardiac arrest as a "sepsis-like" syndrome. Circulation 106:562-568.

213. Servillo G, Vargas M, Pastore A, Procino A, Iannuzzi M, Capuano A, Memoli A, Riccio E, Memoli B (2013) Immunomodulatory effect of continuous venovenous hemofiltration during sepsis: preliminary data. BioMed research international 2013:108951.

214. Bellomo R, Tipping P, Boyce N (1993) Continuous veno-venous hemofiltration with dialysis removes cytokines from the circulation of septic patients. Crit Care Med 21:522-526.

215. Tang W, Chen Z, Wu W, Qiu H, Bo H, Zhang L, Fu P (2013) Renal protective effects of early continuous venovenous hemofiltration in rhabdomyolysis: improved renal mitochondrial dysfunction and inhibited apoptosis. Artif Organs 37:390-400.

216. Laurent I, Adrie C, Vinsonneau C, Cariou A, Chiche JD, Ohanessian A, Spaulding C, Carli P, Dhainaut JF, Monchi M (2005) High-volume hemofiltration after out-ofhospital cardiac arrest: a randomized study. J Am Coll Cardiol 46:432-437.

217. Prowle JR (2015) Measurement of AKI biomarkers in the ICU: still striving for appropriate clinical indications. Intensive Care Med 41:541-543. 
218. Zhang A, Cai Y, Wang PF, Qu JN, Luo ZC, Chen XD, Huang B, Liu Y, Huang WQ, Wu J, Yin YH (2016) Diagnosis and prognosis of neutrophil gelatinase-associated lipocalin for acute kidney injury with sepsis: a systematic review and meta-analysis. Crit Care 20:41.

219. Wasung ME, Chawla LS, Madero M (2015) Biomarkers of renal function, which and when? Clin Chim Acta 438:350-357.

220. Zhang Z, Lu B, Sheng X, Jin N (2011) Cystatin C in prediction of acute kidney injury: a systemic review and meta-analysis. Am J Kidney Dis 58:356-365.

221. Ronco C (2016) Acute kidney injury: from clinical to molecular diagnosis. Crit Care 20:201.

222. Hoste EA, Bagshaw SM, Bellomo R, Cely CM, Colman R, Cruz DN, Edipidis K, Forni LG, Gomersall CD, Govil D, Honore PM, Joannes-Boyau O, Joannidis M, Korhonen AM, Lavrentieva A, Mehta RL, Palevsky P, Roessler E, Ronco C, Uchino S, Vazquez JA, Vidal Andrade E, Webb S, Kellum JA (2015) Epidemiology of acute kidney injury in critically ill patients: the multinational AKI-EPI study. Intensive Care Med 41:1411-1423.

223. Herget-Rosenthal S, Poppen D, Husing J, Marggraf G, Pietruck F, Jakob HG, Philipp $\mathrm{T}$, Kribben A (2004) Prognostic value of tubular proteinuria and enzymuria in nonoliguric acute tubular necrosis. Clin Chem 50:552-558.

224. Aregger F, Uehlinger DE, Witowski J, Brunisholz RA, Hunziker P, Frey FJ, Jorres A (2014) Identification of IGFBP-7 by urinary proteomics as a novel prognostic marker in early acute kidney injury. Kidney Int 85:909-919.

225. Dai X, Zeng Z, Fu C, Zhang S, Cai Y, Chen Z (2015) Diagnostic value of neutrophil gelatinase-associated lipocalin, cystatin $\mathrm{C}$, and soluble triggering receptor expressed on myeloid cells- 1 in critically ill patients with sepsis-associated acute kidney injury. Crit Care 19:223.

226. Gold B, Puertas L, Davis SP, Metzger A, Yannopoulos D, Oakes DA, Lick CJ, Gillquist DL, Holm SY, Olsen JD, Jain S, Lurie KG (2014) Awakening after cardiac arrest and post resuscitation hypothermia: are we pulling the plug too early? Resuscitation 85:211-214.

227. Dragancea I, Rundgren M, Englund E, Friberg H, Cronberg T (2013) The influence of induced hypothermia and delayed prognostication on the mode of death after cardiac arrest. Resuscitation 84:337-342.

228. Kamps MJ, Horn J, Oddo M, Fugate JE, Storm C, Cronberg T, Wijman CA, Wu O, Binnekade JM, Hoedemaekers CW (2013) Prognostication of neurologic outcome in cardiac arrest patients after mild therapeutic hypothermia: a meta-analysis of the current literature. Intensive Care Med 39:1671-1682.

229. Egger M, Juni P, Bartlett C, Holenstein F, Sterne J (2003) How important are comprehensive literature searches and the assessment of trial quality in systematic reviews? Empirical study. Health TechnolAssess 7:1-76.

230. Chen LX, Koyner JL (2015) Biomarkers in Acute Kidney Injury. Crit Care Clin 31:633-648.

231. Maupain C, Bougouin W, Lamhaut L, Deye N, Diehl JL, Geri G, Perier MC, Beganton F, Marijon E, Jouven X, Cariou A, Dumas F (2015) The CAHP (Cardiac Arrest Hospital Prognosis) score: a tool for risk stratification after out-of-hospital cardiac arrest. Eur Heart J pii:ehv556.

232. Concato J, Shah N, Horwitz RI (2000) Randomized, controlled trials, observational studies, and the hierarchy of research designs. N Engl J Med 342:1887-1892. 
233. von Elm E, Altman DG, Egger M, Pocock SJ, Gotzsche PC, Vandenbroucke JP (2007) The Strengthening the Reporting of Observational Studies in Epidemiology

(STROBE) statement: guidelines for reporting observational studies. Lancet 370:14531457.

234. Callaway CW, Donnino MW, Fink EL, Geocadin RG, Golan E, Kern KB, Leary M, Meurer WJ, Peberdy MA, Thompson TM, Zimmerman JL (2015) Part 8: Post-Cardiac Arrest Care: 2015 American Heart Association Guidelines Update for Cardiopulmonary Resuscitation and Emergency Cardiovascular Care. Circulation 132:S465-482.

235. Rosner MH (2009) The pathogenesis of susceptibility to acute kidney injury in the elderly. Current aging science 2:158-164.

236. Weinstein JR, Anderson S (2010) The aging kidney: physiological changes. Adv Chronic Kidney Dis 17:302-307. 
12. Reprints of Paper I-IV 